Chapter 7

\title{
The Performance of Insecticides - A Critical Review
}

\author{
Christian Nansen and Thomas James Ridsdill-Smith
}

Additional information is available at the end of the chapter

http://dx.doi.org/10.5772/53987

\section{Introduction}

As part of minimizing the risk of crop losses due to herbivorous arthropods (here, mainly referring to insects and mites), most of the World's commercial food production systems are subjected to several applications of pesticides before being harvested. Some crops are sprayed 10-20 times, while most field crops are sprayed 1-5 times during the growing season. In the US alone, the average number of insecticide applications ranges from 1-3 for most of the major field crops, and the total annual costs of pesticide applications exceed \$1.3 billion ([1], U.S. Department of Agriculture agricultural statistics services: www.nass.usda.gov/). Several large ag-producing countries publish extensive details on insecticide use, including Australia, and the data presented below were collected from a public website (http://usda01.library.cornell.edu/usda/nass/AgriChemUsFruits//2000s/2008/AgriChemUsFruits-05-21-2008.pdf) on pesticide applications in the US in 2006. A somewhat extreme but also important example is the fresh sweet maize production in the US, which was grown on about 85,000 ha. Based on data from 14 US states, 20 different active ingredients of herbicides were applied an average 1.04 times to fresh sweet maize and amounted to about $2.6 \mathrm{~kg}$ of active ingredients of herbicides per ha. The same data suggested that about $3.5 \mathrm{~kg}$ of 23 different active ingredients of insecticides were applied on average 2.10 times per ha. Similarly, tomato fields (grown on about 42,000 ha in the US in 2006) were treated with 12 different active ingredients of herbicides, which were applied, on average, 1.14 times and the equivalent of about $0.7 \mathrm{~kg}$ of active ingredients per ha. Regarding insecticides, the same tomato fields were treated with 32 different active ingredients, which were applied an average of 3.6 times and equal to about $4.9 \mathrm{~kg}$ of active ingredients per ha. While tomatoes and sweet corn may be close to the top of the list of growing crops receiving pesticide treatments, cauliflower, celery, and many other horticultural crops and fruits are also subjected to intensive pesticide spraying regimes. Thus, farmers acknowledge that weeds and arthropods can potentially cause significant economic losses, and total pesticide application costs are low 
enough to economically justify a very significant and consistent number of applications in almost all crops. It is beyond the scope of this chapter to address the gradually growing market for organic produce and the possible human health and environmental impacts of intensive pesticide spraying regimes. However, it is worth mentioning that - going back to the fresh sweet maize - applying 47 different active ingredients of pesticides (insecticides = 23 , herbicides $=20$, and fungicides $=4$ ) at a total dosage of $6,7 \mathrm{~kg}$ per ha means that (assuming a maize plant density around 65,000 per ha and that about $50 \%$ of the applied pesticide ended up on treated plants) each maize plant received about $0.3 \mathrm{~g}$ of active ingredient of agrochemicals. How much active ingredient ends up in the edible portions of crops varies considerably based on exposure of the harvested plant part, the longevity of chemicals (residual effect) and timing of applications in relation to harvest time. Extensive research efforts are being committed to the short and long term effects of pesticide residues in the food products [2,3]. Despite high levels of pesticides being applied, it is encouraging that publicly available reports, like http://www.ewg.org/foodnews/, suggest that fresh sweet maize does not contain detectable levels of pesticide residues. However according to the same report, other food products (i.e. apples, celery, and bell peppers) quite frequently test positive for pesticide residues.

Several environmental and agronomic/operational factors affect the likelihood of insecticides being applied to a crop. For instance, a comparatively "good growing season", with the right amount and ideal seasonal distribution of rainfall, is equivalent to a high yield potential. A high yield potential means increased risk of potentially high losses incurred by arthropods and weeds, so growers are typically more inclined to apply pesticides to protect a high yield potential. In addition, a "good growing season" may also be conducive to growth of weeds and arthropod pests, which further increases the justifications for applying pesticides, even as a precautionary measure. Among the agronomic factors affecting the likelihood of insecticides being applied, the price of seeds is quite important. A grower may, especially if the prediction is to have a good growing season, decide to plant high-value seeds due to their high yield potential, or because those seeds possess a particular qualitative trait. Similarly, the grower may decide to apply additional (expensive) fertilizer to ensure that the crop grows and yields to its full potential. Planting high-value seeds and "investing" in the crop by applying high levels of fertilizer generally means that growers have lower threshold tolerances for losses incurred. That is, as described in the conventional description of economic injury level and action threshold [4], there is generally a negative relationship between overall value of the crop and the likelihood of pesticides being applied as growers want to protect the growing crop. In other words, investing in high-yielding seeds under favourable conditions may be associated with additional crop protection inputs (such as, pesticide, irrigation, and fertilizer applications), because growers want to take full advantage of the yield potential of the given crop. Another factor increasing the likelihood of insecticide applications is the convenience of "tank mixtures", in which multiple agrochemicals are applied simultaneously. For instance, growers may decide to spray a herbicide just before crop emergence and decide to add a residual insecticide to the formulation to target establishment pests that may or may not be present. That is, growers want to optimize labour and fuel costs, so if they are going to spray fertilizer or herbicides anyway - 
they might as well add a low-cost insecticide to the tank mix and possibly get an added benefit. Estimates suggest that insecticide applications constitute $2-10 \%$ of the crop yield [5-7], but use of tank mixtures obviously decreases the overall application costs. The three examples provided ("good growing season", value of seeds, and tank mixing) are important, because they are not directly related to actual estimates of the pest population density, but they may still lead to a grower applying insecticides. That is, they are factors that raise the concern about possible pest infestations ("good growing season", value of seeds), or they provide economic justification (tank mix) of a pesticide spray application, irrespectively of whether pest populations have been detected in fields. Finally, it is worthwhile to highlight a psychological dimension to pesticide applications, which is that applying pesticides rather than "doing nothing" may give farmers the feeling of "doing something" (in this case spraying pesticides). This aspect is of particular importance in cropping systems in which sampling/monitoring programs are either not an important part of the operational practices, and/or they are deemed practically unfeasible. Increasing sizes of farms mean that the grower may only get to a certain portion of a field every 2-3 weeks or at even less frequent occasions. Obviously, many things can go wrong in a field that is unattended for long time periods, so growers may feel that they cannot afford NOT to apply insecticides - simply as a preventative measure. Frequent and widespread applications of insecticides are understandable, when very little is known about the actual pest population density, large farming areas are managed by only a few people, and when an insecticide can be easily added at a low cost to an existing spray application. Thus, even though growers are generally considered to be "conservative" in their management style, the brief review above clearly outlines many operational and agronomical factors reasons why most crops are treated with numerous insecticide applications in each growing season. Growers are generally low-risk takers, and are therefore accepting to spend considerable resources on pesticide applications according to a philosophy of rather safe than sorry.

\section{Considerations regarding volumes of insecticide formulations}

Due to the emphasis and reliance on insecticide applications, it is worthwhile briefly reviewing some of the basic considerations regarding volume of insecticide formulations and other factors affecting spray coverage and canopy penetration, when insecticides are applied to growing agricultural crops $[8,9]$. Insecticide labels provide information about required application rates for registered combinations of pests and crops and also about volumes of carrier (most commonly water) to be used. Interestingly, these vary considerably mong countries, so the same pesticide may be applied at a considerable range of dosages among different countries [10]. "Adjuvants" are compounds added to spray applications with the purpose of increasing "stickiness" (adherence to crops), provide UV-light protection (increase the residual effect), increase crop leaf penetration, and/or modify droplet sizes (i.e. reduce drift and increase canopy penetration). Use of adjuvants is therefore a very important aspect of spray application performance. Due to costs and logistics of transporting water, aerial fixed-wing insecticide sprays are applied with much lower spray volumes (rarely ap- 
plied in formulations above $50 \mathrm{~L}$ per ha) than when the same insecticides are applied with ground rigs (50-200 L per ha). Other more specialized insecticide delivery systems include fumigations of post-harvest products or of soils, seed treatments (insecticides coated onto planted seeds) and transgenic insertion of toxin producing genes into growing crop plants (i.e. genes from Bacillus thuringiensis in Bt crops). Aerial fixed-wing insecticide applications are often preferred modes of application, when large fields are treated and/or the crop canopy is too high or dense for spray boom applications with a tractor. When insecticides are applied with either aerial or ground rig sprays, the decision on volume of insecticide formulation to be applied to a given field is widely determined by operational considerations, including: 1) size of field, 2) availability and cost of labour, 3) current fuel price, 4) availability of water tanks and/or pumps near the field, 5) height of crop canopy, and 6) whether the insecticide has systemic properties or not (whether it is absorbed through leaf surfaces and translocated within the treated plant - if so, the performance of the insecticide application is perceived to be less influenced by spray coverage and canopy penetration). Other factors more directly linked to the actual pest include: 7) where in the canopy (vertical distribution) the insect pest is most abundant and therefore whether it is important to deliver the insect formulation to a certain portion of the canopy, and 8) the pest's diurnal movement behaviour and therefore whether the spray application has to be completed within a certain time window (for instance, if a pest is highly crepuscular). When applied with modern spraying equipment, the application rate (volume of formulation per ha) is computer controlled mainly through three variables: spray nozzle output (typically delivering mean droplets of $0.05-0.5 \mu \mathrm{m}$ ), boom height above canopy, and speed of vehicle. The practical realities are that aerial insecticide sprays are cheapest but often require contracting of a professional pilot. In Western Australia and many other important agricultural regions, aerial insecticide sprays are frequently about 10 liter per ha, which - assuming that all the spray formulation is deposited on the treated field - amounts to $1 \mathrm{ml}$ per $\mathrm{m}^{2}$. If that $\mathrm{m}^{2}$ has crop canopy (not bare ground), then its total surface area is obviously much higher. [11] examined wheat plants planted at a seeding rate of 180 per $\mathrm{m}^{2}$ and with a specific leaf area of about $30 \mathrm{~cm}^{2}$ per plant, or the equivalent of 2 (both sides) $\times 180$ plants $\times 30 \mathrm{~cm}^{2}=1.08 \mathrm{~m}^{2}$. Thus, the actual surface area per $\mathrm{m}^{2}$ was slightly above $2 \mathrm{~m}^{2}$ when taken the crop surface into account. Furthermore, weather variables are known to greatly impact insecticide spray depositions [1], and issues with pesticide drift are also widely documented [12]. Thus, it seems reasonable to suspect that at least $20 \%$ of the sprayed volume is "lost" (not deposited on the target crop but ends up elsewhere). Summarizing these simple calculations, even a fairly conservative estimate of an aerial spray application suggests that not more than $0.4 \mathrm{ml}$ is applied per $\mathrm{m}^{2}$ to a growing crop. The question raised here is - how likely is it that all insecticide applications deliver enough insecticides to crop leaves so that target pest populations are effectively controlled? In the US, most aerial spray applications are applied at rates around 50 liters per ha, so the spray deposition is likely higher but may still amount to active ingredient leaf coverage in very low concentrations. The calculations presented here may vastly underestimate loss of spray volume due to drift, and they may greatly underestimate leaf areas - especially in dense canopies, so actual spray depositions may be considerably lower. But adhering to the simple calculations presented above, a likely insecticide spray 
application may consist of applying about $0.4 \mathrm{ml}$ evenly to $1 \mathrm{~m}^{2}-$ which should convince most about the concern that is being raised. It is important to underscore that the active ingredient (killing agent) is normally just a small proportion of the spray volume, so the amount of killing agent applied to each $\mathrm{cm}^{2}$ of leaf surface is likely in nanograms. If a contact insecticide is applied - how likely is that target pests acquire a lethal dosage? And if a systemic insecticide is applied - how likely is that the concentration in the vascular tissue is high enough to kill the target pest? Two factors become quite important in the answers to such questions: 1) mobility of the target pest and 2) repellency of the insecticide formulation. Clearly, equivalent to $1-5 \mathrm{ml}$ per $\mathrm{m}^{2}$ are not evenly distributed within $1 \mathrm{~m}^{2}$ of crop, so the target pest will only get in direct contact with the active ingredient if distributions of insecticide formulations and of target pests are spatially correlated (i.e. both are most predominant in the same portion of the canopy), and/or the target pest is very mobile. The point is that heavy (almost exclusive) reliance on contact insecticide applications should be accompanied with strong interest and knowledge about the possible performance and constraints. Or put in bold terms, just because a tractor with a boom sprayer travelled through a field or an airplane flew over a field and a certain volume of pesticide formulation was applied does not necessarily mean that target pest control was accomplished.

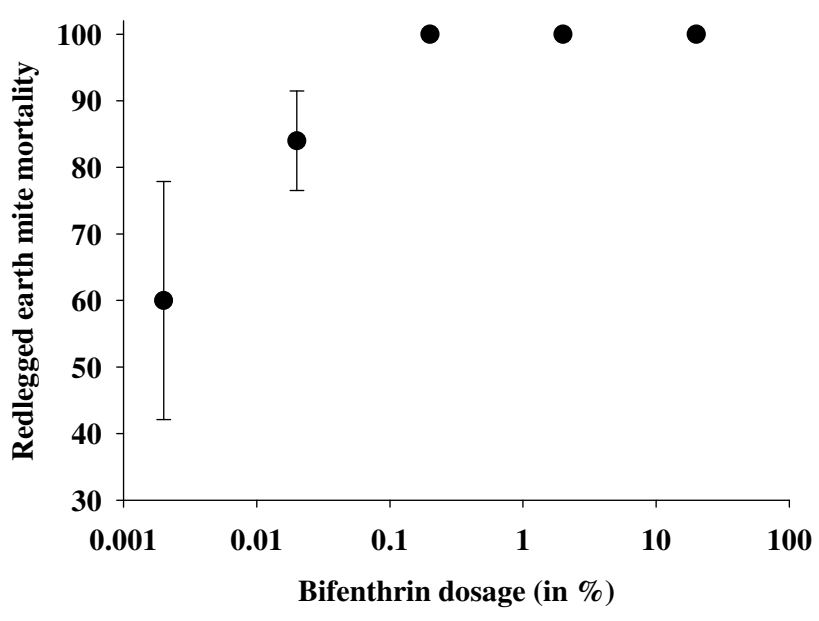

Figure 1. Redlegged earth mite mortality in response to bifenthrin dosage in no-contact bioassay

However, it should be pointed out that insecticides categorized as "contact insecticides" may not always require physical contact in order to cause target pest mortality. Contact insecticides are believed only to kill pests, when insects ingest or get in direct contact with the active ingredient. As an example, bifentrhin is in IRAC (http://www.irac-online.org/eClassification/) class 3A (pyrethroids and pyrethrins), which are sodium channel modulators, and bifenthrin is labelled as a contact insecticide. A simple study was conducted in which formulations of bifenthrin were transferred to a $2 \mathrm{ml}$ Eppendorf tube, which was placed inside a $50 \mathrm{ml}$ plastic container with a lid. We tested the following dosages (\% by volume) of bifen- 
thrin in separate trials: $0 \%$ (positive control), 0.02, 0.20, 2.00, and 20.00. The recommended application rate for control of redlegged earth mite [Halotydeus destructor (Penthaleidae: Acari)] in Australia is 50-100 ml per ha in 50-200 L formulation per ha, and it is normally applied at about $100 \mathrm{ml}$ in $100 \mathrm{~L}$ water, which is equivalent to $0.1 \%$ (by volume) (www.syngenta.com). Redlegged earth mites collected from a field site near York (Western Australia) were transferred to the $50 \mathrm{ml}$ plastic container and provided a single leaf of a suitable host plant (common vetch, Vicia sativa). The rim of the Eppendorf tube containing the bifenthrin formulation was covered with vaseline, so that the redlegged earth mite could not get in direct contact with the insecticide formulation. The lid of the $50 \mathrm{ml}$ plastic container was sealed, so that possible volatilization of the bifenthrin would saturate the air inside the $50 \mathrm{ml}$ plastic container. After 24 hours, the status of the redlegged earth mites was assessed. The results from this bioassay showed a fairly standard log-scaled dosage response in which all redlegged earth mites succumbed when the bifenthrin dosage exceeded $0.2 \%$ (Fig. 1). This simple study highlights important characteristics associated with certain "contact" insecticides, like pyrethroids, as they may actually suppress target pests due to volatilization - i.e. creating a scarce cloud within the crop canopy. And returning to the calculations of applications per $\mathrm{m}^{2}$ described above, volatilization may, at least partially, explain how it is possible that insecticide applications applied at a dosage below $1 \mathrm{ml}$ per $\mathrm{m}^{2}$ are able to provide successful pest control. However, the simple laboratory experiment was conducted in sealed containers, and it is unknown to what extent the micro-environment inside the sealed containers reflects field conditions. More research is needed to investigate the possible roles of factors like insecticide concentration and droplet size on volatilization as a possible mode of action in dense crop canopies, and it is unknown whether volatilization plays a major role across insecticide classes.

\section{Control measures of insecticide applications}

Acknowledging the magnitude of resources spent on insecticide applications, and the possible risk of low insecticide performance due to low and inconsistent insecticide applications it is somewhat noteworthy that there are no widely used quality control measures available. As discussed by [13] and many others, there are numerous factors which can contribute to low performance of a given insecticide application, including: incorrect storage, water $\mathrm{pH}$, wrong concentration of insecticide, nozzles not being turned on, and incorrect application volume. An interesting, but under-utilized resource for assessment of spray coverage, is water sensitive spray cards, which enable growers, consultants, and pesticide applicators to quantify the spray coverage obtained. Water sensitive spray cards are coated with bromoethyl blue, which reacts with water and turn blue-purple depending on dosage of water [14] (Fig. 2b). Although mainly used in applied research projects, they are commercially available through a number of companies and can be used quite effectively to make quantitative assessments of spray applications in response to agronomic variables and weather conditions. [1] used water sensitive spray cards to analyse spray coverage during commercial spray applications in potato fields, of which eight were applied with fixed-wing air- 
plane (spray volume of 48 liter per ha) and six with ground rig (spray volume of 194 liter per ha). During each spray application, 10 water sensitive spray cards were deployed at the top of the canopy in different parts of the field, and both average and range of spray coverages were analysed $(\mathrm{N}=140)$. Canopy penetration data were also obtained from nine of the 14 commercial spray treatments by having additional spray cards placed about $15 \mathrm{~cm}$ from the bottom of the potato canopy. In a recent study conducted in Western Australia, we quantified the "potential spray coverage" of commercial spray rigs by placing water sensitive spray cards at the ground level in a bare field (Fig. 2c). Thus, there was no crop, so the obtained spray coverage represented the highest possible under the given conditions.
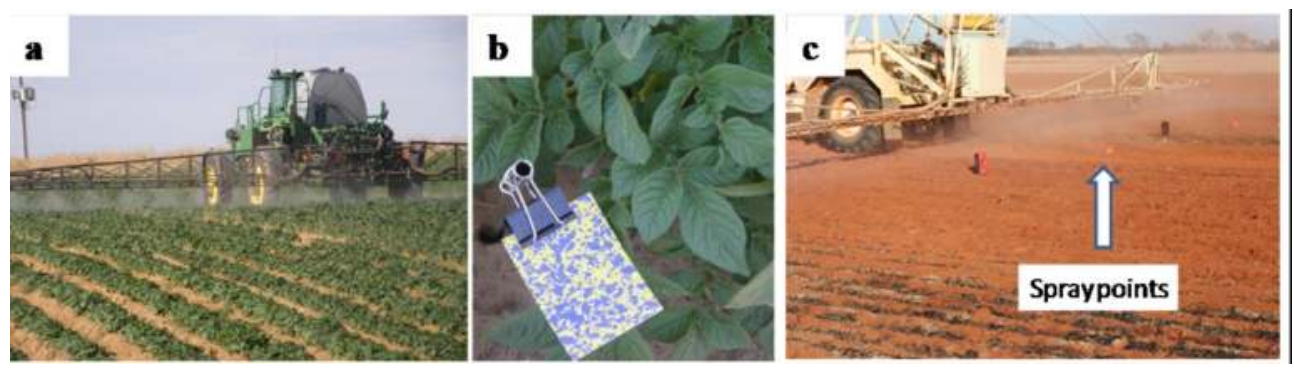

Figure 2. Ground spray rig applications and use of water sensitive spray cards

Weather conditions were recorded, and spray volume (30-130 liter per ha), tractor speed (15-25 $\mathrm{km} / \mathrm{h}$ ) and nozzles type (various types tested) were experimentally manipulated to obtain spray data from a wide range of commercial spray scenarios. Spray data for this study were collected in three combinations of fields and locations, and we obtained data from 77 unique combinations of spray conditions (location, date, spray volume, tractor speed, and nozzle types) and with four replicated spray cards for each combination $(\mathrm{N}=308)$. Fig. 3a shows average spray coverage at the top of the canopy or above bare ground in response to spray volume, and, as expected, there was a highly positive correlation $\left(\mathrm{df}=1,90\right.$, adjusted $\mathrm{R}^{2}=0.790, \mathrm{~F}=340.48, \mathrm{P}<$ 0.001 ). Thus, despite high variability in spraying conditions, spray coverage is clearly driven by volume and reached about $40 \%$, when the equivalent of 200 liter per ha was applied. Average spray coverages for the three data sets (aerial and ground rig applications in Texas and ground rig applications in Western Australia) were examined, and spray coverage was divided by the spray volume applied as a measure of spray performance (Fig. 3b). When applying spray formulations with airplanes, the spray coverage performance was about 0.15 (meaning that for each extra liter per ha, the spray coverage increased, on average, by $0.15 \%$ ), while it was about 0.17 in experimental studies conducted in Western Australia and about 0.24 in ground rig applications in Texas. Thus in terms of "conversion efficiency" (converting spray volume into spray coverage), the ground rig applications in Texas appeared to be most efficient. In addition to comparison of averages, it is important to examine the range of consistency (difference between minimum and maximum) within a given spray application. This information is important, because it may be used to assess the risk of certain portions of treated fields receiv- 
ing sub-lethal treatment levels. Of the 91 spray trials, 66 (73\%) produced spray coverages, in which the lowest spray coverage on a single spray card was below $10 \%$ (Fig. 4). At the same time, the spray range (maximum/minimum) was above 110 in two of the spray applications with airplane and was above 5-fold in 17 (19\%) of the spray trials. Low and less uniform spray coverage, especially with airplane applications, is most likely attributed to using smaller spray volumes and nozzles, which deliver smaller spray droplets and therefore increases the risk of spray drift [12]. Among the spray trial data obtained from Western Australia, the highest spray coverage obtained from a single spray card was about $40 \%$, which is an indicator of the "maximum spray potential". That is, bare ground was sprayed with up to 130 liter per ha, and most growers in this region do not apply more than 90 liter per ha. Consequently, the data collected suggest that it will be very difficult to exceed this level of spray coverage of a growing crop.
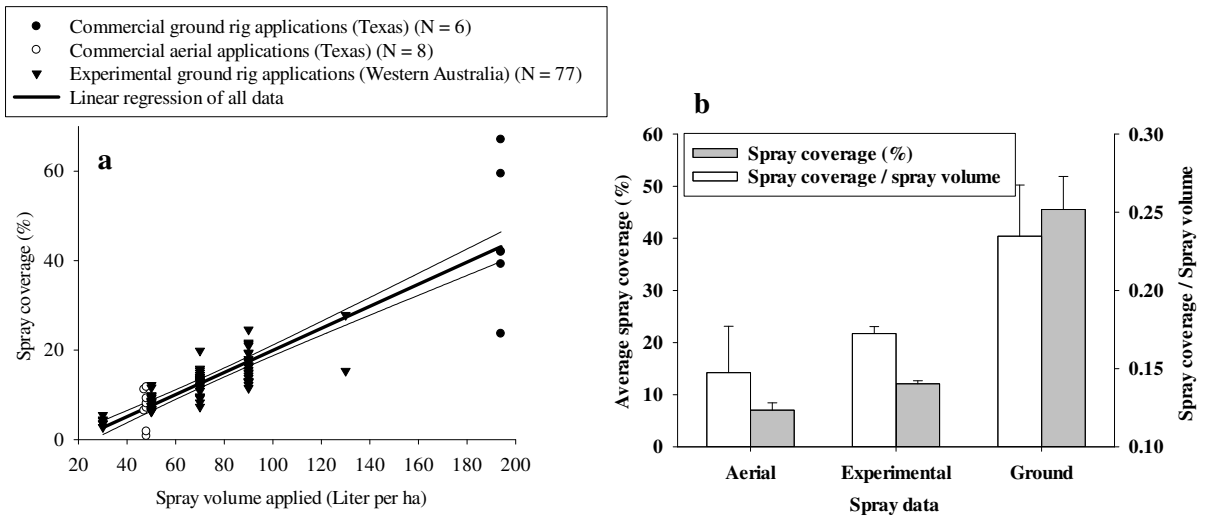

Figure 3. Spray coverage in response to spray volume

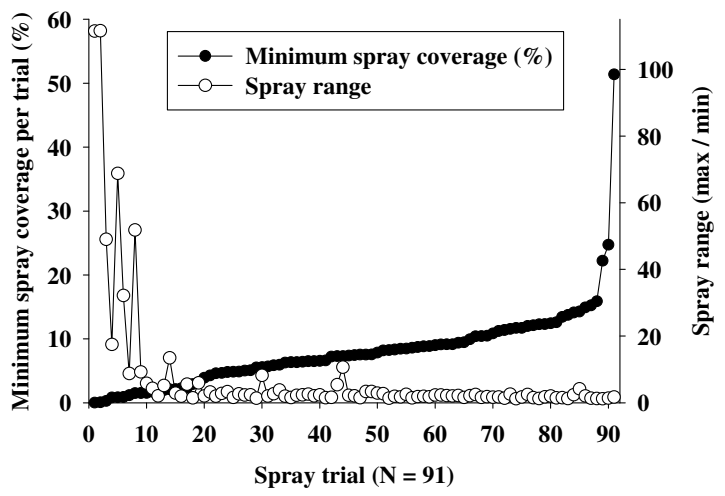

Figure 4. Minimum and range of spray applications 
The final aspect of spray applications discussed here is "canopy penetration" - or the level of insecticide being deposited in the lower portion of a given crop canopy. The spray data presented so far were all collected either from the top of the canopy or above bare ground. Based on analysis of nine of the spray trials from Texas, it was possible to compare spray coverages at the top of the canopy with in the lower portion of a potato canopy above $35 \mathrm{~cm}$ tall. On average, the bottom portion of the canopy received about half the spray coverage of the top portion, and only one of the nine applications provided over $10 \%$ average spray coverage in the bottom portion of the canopy. Published spray coverage studies using water sensitive spray cards have shown that it is not uncommon, especially with aerial spray applications, to obtain spray coverages below $1 \%$ [15-17].

These spray results obtained across a wide range of operational conditions clearly highlight that, although spray volume is the most important variable, other variables need to be taken into account if the goal is to predict the obtained spray coverage. Furthermore, these results underscore that most insecticide spray coverages are likely quite low and highly influenced by weather variables and spray application settings. Thus, it is paramount to develop decision support tools to optimize timing of applications in accordance to weather variables, so that farmers are in a position to apply insecticides with highest likelihood of obtaining good coverage and therefore high performance. Otherwise, it is possible that spray applications of low and inconsistent insecticide dosages contribute to resistance development in target pest populations $[10,18]$.

\section{Arthropod pests and insecticide resistance}

[13] pointed out that insecticide resistance is among the most significant challenges to food production systems and to public health through management of insect vector born diseases. There are clear indications that many major pests are able to develop physiological and or behavioural insecticide resistance to a large number of insecticides. In this context, physiological insecticide resistance is defined as genotypes being able to tolerate high dosages of neurotoxic ingredients, which are lethal to most individuals of the same species. The most common physiological resistance mechanisms are [19]: 1) catabolic processing of the active ingredient, 2) changes in binding sites that are targeted with a given toxin, 3) decreased uptake rate, and 4) binding of toxin to sites with no toxic effect. Behavioural resistance [20] has been documented for the past 40 years, and it is interpreted as a behavioural adaptation, which reduces the likelihood of target pests acquiring a lethal dosage of insecticide. Behavioural insecticide resistance has mainly been discussed in the context of "bait aversion", in which, for instance glucose based bait for control of cockroaches [21-23] no longer works, because the cockroaches avoid the bait. However as discussed below, it also seems plausible that behavioural insecticide resistance may develop in response to low and incomplete spray coverage. Concerns about behavioural insecticide resistance may be of particular concern when target pests predominantly occur on the abaxial (lower) side of crop leaves and insecticides are not translaminar or systemic. For instance, in a simple study in which either one or both sides of potato leaflets were treated, [24] showed that for some insecticides pota- 
to psyllid mortality was much lower when only one side was treated compared to when both sides of the leaflet were treated. These findings were interpreted as potato psyllids [Bactericera cockerelli [Sulc] (Homoptera: Psyllidae)] moving away from (avoiding) the treated leaflet side when given a choice between treated and untreated sides.

The first reported incidence of physiological pesticide resistance was of San Jose scale [Quadrispidiotus perniciosus (Comstock) (Homoptera: Diaspididae)] to lime sulphur in 1914 [25]. Since then, more than 550 arthropod species have been reported as being resistant to one or more pesticides [13]. However already in 1977, more than 364 species of arthropods were reported to show physiological pesticide resistance [26], 447 species in 1984 [27], and [28] 503 species in 1991. A few examples of documented physiological resistance against active ingredients are presented here and are based on data from the Arthropod Pesticide Resistance Database (APRD, http://www.pesticideresistance.org/): 1) two-spotted spider mite (Tetranychus urticae Koch, Acari: Tetranychidae) has developed resistance to 93 active ingredients, 2) diamondback moth (Plutella xylostella L, Lepidoptera: Plutellidae) has developed resistance to 82 active ingredients, 3) green peach aphid Myzus persicae (Sulzer) (Homoptera: Aphididae) has developed resistance to 74 active ingredients, 4) Colorado potato beetle (Leptinotarsa decemlineata (Say), Coleoptera: Chrysomelidae) has developed resistance to 51 active ingredients, 5) silverleaf whitefly (Bemisia tabaci Gennadius, Homoptera: Aleyrodidae) has developed resistance to 46 active ingredients, 6) cotton bollworm / corn earworm (Helicoverpa armigera Hübner, Lepidoptera: Noctuidae) has developed resistance to 44 active ingredients, and 7) beet armyworm (Spodoptera exigua Hübner, Lepidoptera: Noctuidae), has developed resistance to 29 active ingredients. Diamondback moth was the first pest to become resistant to DDT (dichlorodiphenyltrichloroethane) [29, 30]. From the mid-1990s, the use of formulations of toxins derived from strains of the soil borne bacterium, Bacillus thuringiensis (denoted Bt toxins) have been promoted to control key lepidopteran and coleopteran pests and at the same time preserve natural enemy populations within crops [31]. Due to its high efficiency, low cost and simple application, Bt-based pesticides rapidly became used for control of many pests, and diamondback moth was the first insect pest to become resistant to Bt toxins [32-34]. Thus, certain characteristics in the diamondback moth genome, its biology, and its interactions with food cropping systems seem to expose an incredible adaptability and responsiveness to imposed pesticide-induced selection pressures. Consequently, [13] made the important point that while there is a steady increase in reported cases of resistance, the number of new species with documented resistance is not increasing nearly as fast. It is therefore important to consider that the most important insect pests will likely continue to develop resistance to the insecticide pressures that are imposed upon them, and that the ability to develop physiological resistance to insecticides may be one of the driving selection pressures for species to become pests. That is, the economically most important arthropod pest species may share certain common denominators, which enable them to be successful under commercial/agricultural conditions with high levels of selection pressure imposed by insecticide treatments. It may be argued that insight into such denominators is critically important for development of future pest management programs, as it may open avenues for management strategies that rely less on insecticides. With less reliance on insec- 
ticide applications, pest populations would be under less insecticide-induced selection pressure, which would decrease the risk of pest populations developing insecticide resistance.

When addressing concerns about risk of insect pest populations developing physiological resistance and how management practices can be developed under commercial settings to reduce this risk, it is worthwhile setting the general context. Firstly, we wish to emphasize that there are only two extreme scenarios, which do not potentially lead to development of physiological resistance in target pest populations: 1) always applying an insecticide dosage low enough so that all genotypes survive, 2) applying a high enough dosage to ensure that individuals of all genotypes die. Obviously, the first option is of no interest to growers, as it means zero pest control, and therefore represents waste of resources. As already described in detail based on the analysis of water sensitive spray cards, the second option is in most cases unfeasible from a practical standpoint, and it may also imply very high economical costs. This means that under real-world conditions, applications of insecticides are always imposing a selection pressure on target pest populations.

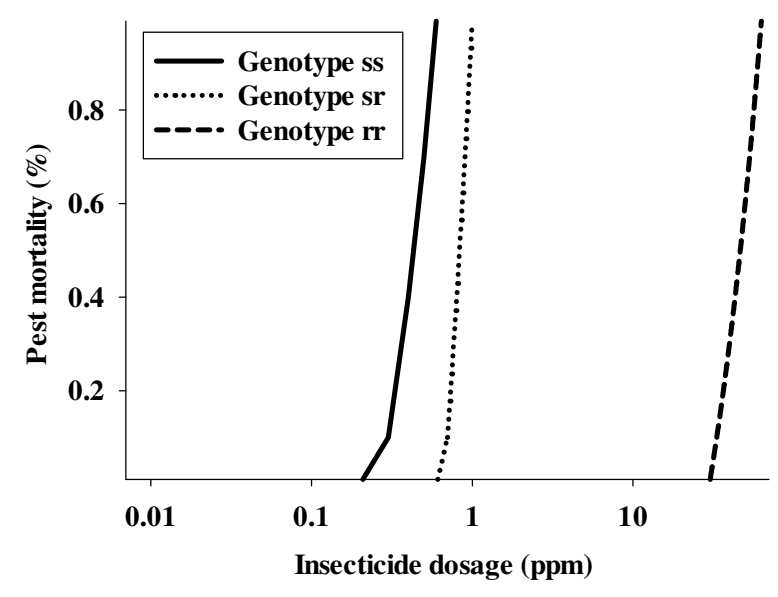

Figure 5. Dosage response

The important point is that the mortality of a given pest individual is NOT random within a pest population: an individual will only succumb to an insecticide application, if the individual is actually susceptible to the pesticide and exposed to a dosage above a certain level (minimum lethal dosage). Moreover, pest individuals within a population vary in their ability to tolerate an insecticide, and - based on their behaviour - vary in likelihood of getting exposed to the insecticide. The intraspecific variation in tolerance to an insecticide is linked to the fact that the mode of action of the vast majority of insecticides is very specific and associated with allelic variation at one (monogenic) or two loci. That is, the insecticide operates by interfering with a very specific metabolic function, but even the slightest change in binding site (induced by mutation at a single locus) may compromise the performance of the 


\begin{tabular}{|c|c|c|c|c|}
\hline \multirow{2}{*}{ Insecticide dos age } & \multicolumn{3}{c|}{ Genotype } & Total \\
\cline { 2 - 4 } \multicolumn{1}{c|}{ PPM } & ss & sr & rr & Population \\
\hline 0.00 & 9980.01 & 19.98 & 0.01 & 10000.00 \\
\hline 0.10 & 9980.01 & 19.98 & 0.01 & 10000.00 \\
\hline 0.20 & 9980.01 & 19.98 & 0.01 & 10000.00 \\
\hline 0.30 & 8982.01 & 19.98 & 0.01 & 9002.00 \\
\hline 0.40 & 5988.01 & 19.98 & 0.01 & 6008.00 \\
\hline 0.50 & 2994.00 & 19.98 & 0.01 & 3013.99 \\
\hline 0.60 & 0.00 & 19.98 & 0.01 & 19.99 \\
\hline 0.70 & 0.00 & 17.98 & 0.01 & 17.99 \\
\hline 0.80 & 0.00 & 11.99 & 0.01 & 12.00 \\
\hline 0.90 & 0.00 & 5.99 & 0.01 & 6.00 \\
\hline 1.00 & 0.00 & 0.00 & 0.01 & 0.01 \\
\hline & & & & \\
\hline
\end{tabular}

Table 1. Dosage response

insecticide, so pest individuals possessing such changes will have a higher chance of survival, while individuals without the specific allele will be eliminated. If the insecticide resistance is monogenic, and only two alleles exist ( $r=$ resistant and $s=$ susceptible) - dosage response curves for the three genotypes are typically presented with mortality increasing along a logarithmic dosage scale [27]. In a theoretical example of a pest population of 10,000 individuals (Fig. 5), individuals of genotype ss may be expected to succumb when the insecticide dosage ranges between 0.3-0.6 ppm, sr individuals when the insecticide dosage ranges between 0.6-1.2 ppm, and rr individuals when the insecticide dosage is above $30 \mathrm{ppm}$. If $\mathrm{p}=$ 0.001 is the allele frequency of $\mathrm{r}$ and $\mathrm{q}=0.999$ is the allele frequency of $\mathrm{s}$, and the genotypes occur in Hardy-Weinberg proportions, then the demographic composition of the pest population in response to insecticide dosage is as outlined in Table 1. It is seen that subjecting a pest population to a dosage above $0.5 \mathrm{ppm}$ causes a $>99 \%$ reduction of the overall population, but if it less than $60 \mathrm{ppm}$ it also increases the proportion of resistant individuals in the remaining pest population. And although this fairly simple relationship between survival of genotypes and insecticide dosage has been investigated intensively over the last 3-4 decades and been greatly expended upon - it illustrates the core challenge that insecticide based pest control is faced with: Growers want to suppress as large a proportion of the pest population as possible to minimize the economic loss they incur, and therefore apply high dosages of insecticides. However, they are not able to apply a high enough dosage to completely suppress all pest individuals, so a selection pressure is imposed on the pest populations and the end result may be that the pest population develops physiological resistance because it is practically impossible to kill all the homozygous resistant genotypes.

In this brief and very general discussion of the importance of insecticide dosages, it is important also to mention that the efficiency or performance of an applied insecticide declines over time. The term "residual effect" is used to describe the longevity of the time period in which a given insecticide provides effective pest control, and rarely (continuous expression 
of Bt toxins in transgenic Bt crops would be an exception) will an insecticide have a residual effect after 7-10 days. In a study of abamectin, [24] conducted experimental sprays of potato leaflets in different vertical portions of a potato canopy under field conditions. During time intervals after spraying, treated and untreated leaflets were collected and used in bioassays with potato psyllids to determine the adult psyllid mortality over time. Based on this study, [24] concluded that the residual effect of abamectin is less than 48 hours. Although most insecticides have longer residual effect than abamectin, the example highlights the challenge that the effective dosage applied will decline over time, so pest individuals that are not affected immediately after application may not be exposed to a lethal dosage. For instance at the time of application, pest individuals may not be present at a vulnerable stage (for example mite eggs are not killed by systematic sprays whereas active adult mites will be killed), or the life stage may not be exposed to contact with chemicals (this is especially important for larvae of insects feeding on roots of plants in the soil). This problem or challenge, with not all life stages being equally susceptible to an insecticides application, becomes an even larger issue, if multiple pest species are present, and these different species occur in different parts of the crop canopy, have different movement patterns within the canopy, show difference in terms of seasonal population dynamics, and also have different migration patterns between the given crop and neighbouring alternative hosts. Immigration by pest populations deserves to be highlighted as a serious constraint: if a pasture or field is treated and all present pest individuals are killed but high immigration means that a new population of pest individuals move into the given field or pasture a shortly after. If so, a grower might think that the insecticide application "didn't work" - but the reality is that the immigration rate of the pest needs to be taken into account when assessing what insecticide to apply and when to apply it. It is not practically feasible to apply insecticide specifically for each pest present separately and so inevitably each application event may effectively control some species or life stage, while other pest individuals will be exposed to sublethal dosages.

In addition to concerns associated with physiological resistance of target pest populations, behavioural resistance may possibly develop in response to incomplete pesticide coverage, as target pests are given a "choice" between treated and untreated surfaces. If the target pest is able to discriminate between treated from untreated surfaces and eventually avoid treated surfaces, the pest will be less exposed to the insecticide. Consequently, the ability to avoid treated surface becomes a strong selection pressure, which can lead to development of behavioural-based resistance, and it has been demonstrated in diamondback moth populations [35, 36], German cockroaches (Blatella germanica L. [Blattodea: Blattellidae] [23, 37], and maize weevils (Sitophilus zeamais Motschulsky [Coleoptera: Curculionidae]) [38]. [39] demonstrated that spider mites are repelled by the contact miticide, propargite. In a recent study of spider mites on cotton plants, [40] quantified the consequences of behavioural avoidance and based on theoretical modelling showed that behavioural avoidance can have significant impact on population dynamics.

Summarizing this section, the ability to develop physiological resistance to insecticides is one of the key characteristics of the most economically important arthropod pests. There are widespread examples of pests developing behavioural resistance by avoiding treated leaf 
surfaces or baits containing the active ingredient. With regards to contact insecticides, it is possible that a combination of frequent and low performing pesticide applications creates a selection pressure which favours pest individuals avoiding treated portions of crop leaves, as individuals: 1 ) have ample opportunity to recover after sub-lethal exposures and therefore "learn" to avoid insecticide treated surfaces, and 2) will be under a directional selection pressure for non-feeding on treated surfaces. However, we are unaware of experimental studies actually addressing the possible relationship between insecticide spray coverage in agricultural field pest populations and behavioural resistance in target pest populations. It is likely that the most important pests will continue to develop resistance to insecticides, as certain traits in their biology and/or ecology appear to enable them to adapt to these severe selection pressures. Thus, continued emphasis on almost exclusive insecticide-based pest control may be a strategy that deserves serious revision, as it seems to play to one of the key "strengths" (their adaptability) of the most important pests. The fundamental challenge is therefore to develop management practices, which minimize the risk of resistance development, and theoretical modelling is critically important in this context, because it can be used as a working tool to examine changes in population genetics over time and under different selection pressures. That is, instead of waiting until growers actually face the severe consequences of insecticide resistance, we can use theoretical modelling to predict its progress and hopefully find ways to slow it down.

\section{Sensitivity analysis of physiological resistance development to pesticides}

Studying resistance development in controlled populations is, in addition to being highly laborious, associated with some basic concerns. The frequency of resistance alleles in a given pest population is typically extremely low (one in a 1,000 or less) and therefore requires individual analysis of very large numbers (millions or billions) of individuals. And when small laboratory populations are subjected to intensive insecticide based selection pressure, there is a considerable risk of unforeseen recessive genetic defects being expressed and affecting the observed population dynamics. [27] provided an in depth discussion and review of the concerns related to rearing of laboratory cultures for studies of how fast pest populations are able to develop resistance. In brief, they mentioned how the rearing may lead to "genetic bottlenecks" or selection pressures, which are different from those imposed on field populations. Consequently, it is highly likely that a laboratory strain carries major resistance alleles at frequencies that are very different from field pest populations and that studies of resistance development in laboratory strains therefore are unable to mimic actual field conditions. Finally, numerous factors are considered important when assessing the likelihood of a pest population developing physiological resistance, and based on [41], they can be divided into four categories: 1) genetic factors (i.e. frequency, dominance, and expressivity of resistant alleles and their interactions with other alleles, past selection pressures in pest population, and whether the resistance is monogenic or polygenic), 2) biological factors (fecundity, generation and development times, mating be- 
haviour, level of polyphagy, migration/dispersal and mobility, fitness costs of resistance development, and feeding biology), 3) operational (mode of action of insecticide, residual effect of the insecticide, adjuvants added to sprayed formulations, timing of applications in relation to pest population development (which life stages are targeted), dosage applied, crop density at the time of application, type of spray nozzles used, height of spray boom, and 4) weather conditions (which are known to greatly affect spray depositions, see above). With such complexity of factors involved, it is not surprising that much of the current understanding of pesticide resistance development in pest populations is based on genetic population modelling and theoretical sensitivity analyses [10, 42-45]. Such modelling efforts are in many ways constructive and can be used to develop strong justifications for specific research projects and management practices. However at the same time, their validity depends on the assumptions used in their construction [46, 47].

The following section is a sensitivity analysis based on genetic population modelling, which expands on work presented in two theoretical modelling papers [26, 41]. Although published almost 40 years ago, these studies present the basic modelling framework needed to examine fairly simple/basic questions about resistance development. Results presented here are based on a theoretical arthropod pest population " $X$ " with an initial population of 11,000 individuals followed over 20 subsequent generations, and it is assumed that: 1) adults only give offspring in one generation, 2) each generation was exposed to a single insecticide application, 3) resistance development occurs in a single locus with two alleles, $r$ (resistant) and s (susceptible), 4) p $=0.0001$ is the gene frequency of $r$ and $q=0.9999$ is the gene frequency of s, 5) genotypes occur in Hardy-Weinberg proportions, 6) dominance is assumed to be intermediate, so that, under insecticide based selection pressure, the survival of genotypes is rr > rs > ss, and 7) resistance was associated with a "fitness cost", which is defined as resistant genotypes having lower fitness than susceptible genotypes in the absence of the particular insecticide [45]. Based on a review by [45] of 77 studies of Bt resistance, it was assumed that physiological insecticide resistance was associated with a "fitness cost" of $15.5 \%$ for each allele. Although the possible importance of "incomplete resistance" [42] and "hybrid vigor" [45] have been highlighted, these factors were not included in this analysis. The following sensitivity analysis of $\mathrm{r}$ allele frequency and pest population density is based on 1,000 simulations of different scenarios with random variables. Similar to [26], the population density after each discrete generation, $\mathrm{N}^{\prime}$, was assumed to be density-dependent and described by the following equation 1 :

$$
\begin{gathered}
N^{\prime}=\left[W_{r r} \times N_{r r} \times \exp \left(r_{r r} \times\left(K-N_{a} / K\right)\right]+\right. \\
{\left[W_{r s} \times N_{r s} \times \exp \left(r_{r s} \times\left(K-N_{a} / K\right)\right]+\right.} \\
{\left[W_{s s} \times N_{s s} \times \exp \left(r_{s s} \times\left(K-N_{a} / K\right)\right] .\right.}
\end{gathered}
$$

In which $\mathrm{W}$ denotes the survival of each genotype, $\mathrm{N}$ denotes the number of adults in the previous generation, $\mathrm{K}$ denotes the carrying capacity, and $\mathrm{N}_{\mathrm{a}}$ denotes the initial population. 
In the following, we present modelling results from two scenarios, and the main point is to demonstrate some of the advantages of using modelling as part of demonstrating how physiological insecticide resistance appears to develop across a very wide range of scenarios.

Scenario 1: Effects of reproductive fitness and crop suitability on resistance development. Using Equation 1 to estimate total population and $\mathrm{r}$ allele frequency over 20 generations, the following settings for allele frequencies were kept constant: $p=0.0001$ and $q=0.9999$, and survival rates of the 3 genotypes $(\mathrm{W})$ were: $\mathrm{W}_{\mathrm{rr}}=1, \mathrm{~W}_{\mathrm{rs}}=0.5, \mathrm{~W}_{\mathrm{ss}}=0$. Thus, in this scenario, none of the susceptible individuals $\left(\mathrm{W}_{\mathrm{ss}}\right)$ were expected to survive and did therefore not contribute to the sensitivity analysis. [26, 41] assumed the reproductive fitness of pest population $X$, " $r$ ", to be constant and equal to $\ln (5)$ between generations, and many subsequent and more recent studies have also been based this assumption. Here, the reproductive fitness of the resistant genotype was assumed to vary randomly from $\ln (3)-\ln (7)$ (random numbers with two-decimal points) between generations. With the reproductive fitness of the resistant genotype varying randomly between $\ln (3)-\ln (7)$ and the fitness cost of resistance being $15.5 \%$, that of the heterozygous genotype, $r_{r s}=r_{r r} \times 1.155$. A constant carrying capacity implies that a certain habitat can sustain the same pest population in all growing seasons and irrespectively of regional differences in environmental conditions. Seasonal variations in growing conditions (i.e. drought stress levels and fertilizer regimes) clearly cause marked variations in number of pest individuals a crop plant can harbour. For instance, nutritional composition of crops can vary considerably in response to drought stress [48-51] and is known to vary considerably between growing seasons [52, 53]. [54] estimated varying carrying capacity of the milkweed-oleander aphid [Aphis nerii Boyer de Fonscolombe (Hemiptera: Aphididae) on one of its host plants, milkweed (Asclepias tuberosa) in response to nitrogen applications. Based on data collected under controlled conditions, the authors obtained ranges from 29.5-35.1 (19\%) aphids. Thus, here we assumed a 20\% random variation in carrying capacity between growing seasons ( $\mathrm{K}$ ranging randomly from 10,000-12,000 between subsequent generations).

In all 1,000 scenarios, the initial pest population was reduced by $>99.9 \%$ after the initial infestation $(\mathrm{N}=11,000)$ was exposed to the first insecticide application. After the initial knock-down, the pest population remained low for about eight generations, after which the pest population density started to increase steadily (Fig. 6a). Almost complete insecticide failure (back to initial pest population density due to complete physiological resistance) was achieved within 20 generations. Comparison of the average curve of the pest population density under varying reproductive rate and carrying capacity and that of fixed variables [with constant reproductive fitness $\left(\mathrm{W}_{\mathrm{rr}}=5, \mathrm{~W}_{\mathrm{rs}}=5.775\right.$ and carrying capacity $(\mathrm{K}=$ 11,000)] suggested that incorporation of variability into reproductive fitness and carrying capacity had limited effect. That is, the average of the 1,000 simulations was very similar to that of fixed variables except for a few and rare simulations (indicated by the curve of maximum pest population) reduced the time to complete physiological resistance by a few years (shifted the curve to the left). Fig. $6 \mathrm{~b}$ showed that varying crop carrying capacity and reproductive fitness had almost negligible impact on the $r$ allele frequency in the pest population (as expressed by the range of minimum and maximum curves). Most sensitivity 
studies of genetic populations are based on large populations (i.e. 10,000 individuals), and it is assumed that individuals mate randomly within these large populations. This is highly unlikely and is the main reason why recent genetic population modelling uses a meta-population modelling approach, in which a large population is considered to be composed of many smaller and somewhat segregated populations. Such meta-population based approaches include assumptions about movement between populations and sizes of sub-populations, and these assumptions were not included in this analysis. Another approach is to use individual-based modelling [10]. Based on the analysis of scenario 1, we have highlighted that the influences of incorporating varying crop carrying capacity and reproductive fitness into modelling predictions of population densities over 20 generations were modest, when the fitness cost was kept constant (15.5\%), and they had negligible effect influence on $r$ allele frequency.
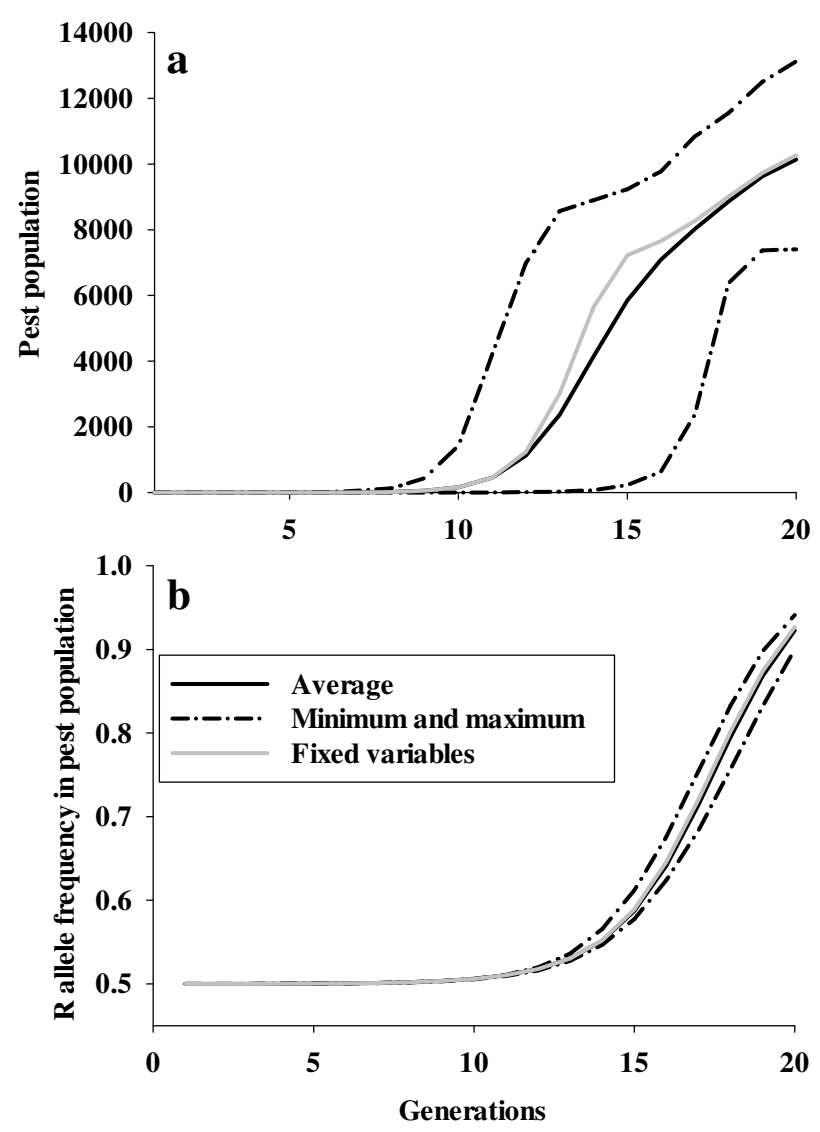

Figure 6. Effects of varying reproductive fitness and carrying capacity 
Scenario 2: Effect of varying pesticide spray performance. In this scenario, varying reproductive fitness rates and carrying capacity were maintained as described in scenario 1 . The survival rate due to pesticide applications was kept constant for the homozygous resistant $\left(\mathrm{W}_{\mathrm{rr}}=1\right)$, but this scenario was conducted with varying survival rates of $\mathrm{W}_{\mathrm{rs}}$ and $\mathrm{W}_{\mathrm{ss}}$. That is, it was assumed that low and inconsistent spray coverage would in some generations increase the survival of $W_{r s}$ and $W_{s s}$. The basis for investigating this scenario with varying survival rates of $W_{\mathrm{rs}}$ and $\mathrm{W}_{\mathrm{ss}}$ was supported by the field spray data presented in Fig. 3: Out of the 91 insecticide spray data sets, several data sets showed spray coverage ranges above 50 times (difference between minimum and maximum). It therefore seems reasonable to assume that there is considerable variation in insecticide dosages and therefore survival rates of subsequent pest population generations. Consequently, a random number function was used to generate survival rates from 0.3 to 0.7 for $\mathrm{W}_{\mathrm{rs}}$ and survival rates below 0.5 were considered to be equal to 0.5 . In other words, the random function generated one of five outcomes $(0.3,0.4,0.5,0.6$, or 0.7$)$ with equal probability, and three of these $(0.3,0.4$, and 0.5 or $60 \%$ of the outcomes) were equal to 0.5 , and there was a $50 \%$ chance $[(0.7-0.5) \times 100 /(0.7-0.3)]$ of increased survival due to low and inconsistent spray coverage for $\mathrm{W}_{\mathrm{rs}}$ genotypes. Regarding genotype $W_{\mathrm{ss}}$ the same random function approach was applied to generate random survival rates from -0.2 to 0.2 , and all rates equal to or below 0 denoted no survival. In other words, there was about $50 \%$ chance of $\mathrm{W}_{\mathrm{ss}}$ genotypes contributing at least some offspring to the next generation. As in scenario 1, a 15.5\% fitness cost was maintained for each resistant allele, which meant that the reproductive fitness of $r_{r s}=r_{r r} \times 1.155$ and that of $r_{s s}=r_{r s} \times 1.155$. In other words, the survival of $\mathrm{W}_{\mathrm{ss}}$ genotypes had the potential of contributing substantially to subsequent generations in simulations with $\mathrm{W}_{\mathrm{ss}}>0$.

In this scenario with varying survival rates of $\mathrm{W}_{\mathrm{rs}}$ and $\mathrm{W}_{\mathrm{ss}}$ the population density after the initial knock-down was, on average, $95 \%$, but there were simulations in which it was below $80 \%$. It should be expected, that increased survival due to low and inconsistent pesticide applications increased the pest population growth during 20 generations, but, in comparison with scenario 1 , the effect on pest population was actually quite modest (Fig. 7a). As an example, in scenario 1 (with no survival of homozygous susceptible individuals) the average population density was about 6,000 individuals after 15 generations, while it was about 7,000 individuals in scenario 2 . Thus, with half of the simulations allowing 1-20\% survival of homozygous susceptible individuals there was only a modest increase in average pest population density. However as indicated by the maximum curve, there were indeed scenarios in which high pest populations were achieved within about 11 generations. With fixed variables and assumption about Hardy-Weinberg allele frequencies, the $\mathrm{r}$ allele frequency obviously stayed above $50 \%$ and increased as the homozygous resistant genotype increased in relative proportion. Fig. $7 \mathrm{~b}$ showed, as expected, that the varying survival of homozygous susceptible individuals ( when $\mathrm{W}_{\mathrm{ss}}>0$ ) led to a decrease in $r$ allele frequency. In fact after 20 generations, none of the 1,000 simulations led to a higher $r$ allele frequency than $93 \%$, while with fixed variables it was $>96 \%$. In other words, this simple exercise suggested that by allowing susceptible genotypes some level of survival, low and inconsistent pesticide applications appear to postpone development of complete resistance. However, low and inconsistent pesticide applications also lead to higher risk of high pest population densities (comparing Fig. 6 a and 7 a) and therefore crop damage and corresponding yield 
losses. Thus, here it is highlighted that with a consistent selection pressure (all generations of pest individuals subjected to a pesticide applications) the performance of pesticides and negligible development of resistance are antagonistic. In other words, growers should not expect to accomplish both: a high-performing pesticide application will create a strong selection pressure and therefore lead to resistance development. On the other hand, low and inconsistent pesticide applications appear to reduce the likelihood of pest populations developing resistance, but it will also reduce the performance of pesticide applications. However, it is likely that low and inconsistent insecticide applications increase the risk of target pest populations developing behavioural resistance, but that is not incorporated into the modelling presented here. A recent modelling based study of herbicide resistance in weeds addressed this specific question about the effect of dosage [10]. The authors concluded that in cases of monogenic resistance, pesticide dosage had negligible effect on the number of generations before complete failure. However, they also pointed out that in cases of resistance being "non-target specific" (i.e. metabolic and/or polygenic resistance), there is growing evidence of herbicide resistance developing faster under low-dosage selection pressure. There are important differences in factors leading to resistance in weed and insect pest populations (i.e. reproduction/mating biology, generation time, and dispersal strategies), so it may not be accurate to assume the exact same responses by insects and weeds. However, it is clear that reliable and accurate sensitivity analysis of how certain variables affect the likelihood of a pest population developing resistance requires that the underlying genetics are sufficiently understood (especially whether resistance in mono- or polygenic).

\section{Some realities associated with rotation of insecticides}

It may be argued that the scenarios outlined above are far too simplistic and do not take into account that growers are rotating insecticides as part of resistance management practices. The core of resistance management programs is to rotate between active ingredients, as cross-resistance to multiple insecticides is much less likely to develop. Regarding transgenic crops expressing Bt toxins, incorporation of non-treated refuges in cropping systems is also being advocated [see [45] for review). We are unaware of recommendations about non-treated refuges for any other insecticide treatments. Consequently rotation of classes of active ingredients is the only widespread resistance management strategy, but there are crop-pest systems in which only a few active ingredients are registered for use. For instance in Western Australia, there are three species of aphids [The cabbage aphid, Brevicoryne brassicae (L.), the turnip aphid, Lipaphis erysimi Kalt, and the green peach aphid, Myzus persicae (Sulzer) (Hemiptera: Aphidae)] attacking canola during the flowering/podding period - yet only ONE insecticide (Pirimicarb 500) is registered for use against these pests! In addition, active ingredients are increasingly being faced out (banned) - so growers are left with only a few options. And if one particular pest is under a single insecticide selection pressure in one cropping system, then this may be the source for a resistant pest population to emerge. In addition, rotation of insecticides is only an effective option as long as cross-resistance is close to negligible, although there are ample examples of arthropod pests developing resistance to a many 


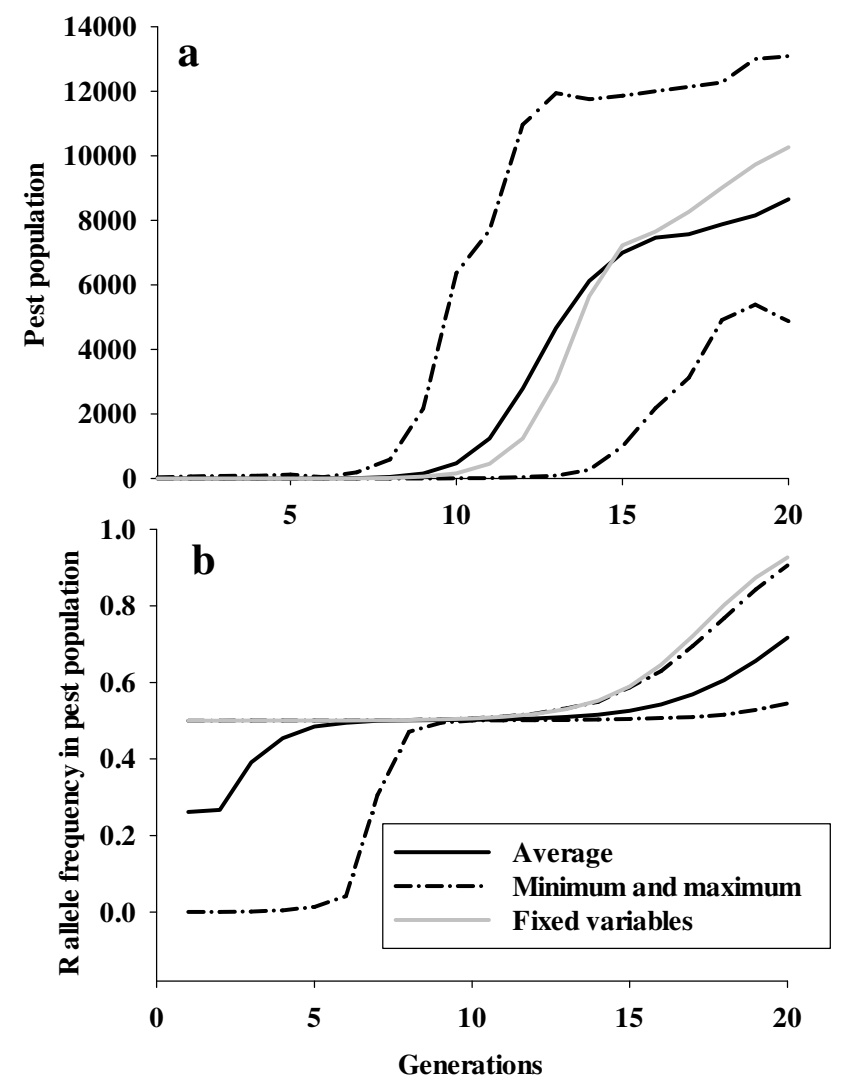

Figure 7. Effects of varying spray application performance

insecticides (examples listed above). Another important aspect of insecticide rotation is that during the last 50 years, it has been a successful but short-term strategy to rely on a continuous development of new pesticides, so the steady increase in insecticides losing their performance has been less of an issue. However, there seem to be a trend of chemical companies registering fewer new insecticides, and at the same time older chemistries are being faced out. So the total number and the diversity of commercially available insecticides are decreasing. And with less available options to choose from, there is obviously an increased overall risk of resistance development. The declining number of new insecticide registrations is very interesting and likely explained by a complex of factors. But it is clear that, in recent years, regulatory bodies have increased the amount of risk assessment studies required for a successful registration, and many of these quite expensive. Thus, chemical companies are less inclined to register new insecticides unless they target very large commercial markets. So risks of insecticide resistance, due to few insecticide alternatives to choose from, may be of particular concern to comparatively smaller 
markets (cropping systems). In addition to chemical companies being less inclined to register new insecticides due to registration costs, it also means that newly registered insecticides are often considerably more expensive than older insecticides, because the registration costs are passed on to end-users. And a stark difference in price between old and new insecticide obviously creates an economic incentive for continuing insecticide treatment programs based almost exclusively on old/less-expensive insecticides. Thus, resistance in target pest populations may continue to develop due to lack of rotation of insecticides, because growers are unwilling to incorporate newer and more expensive insecticides into their insecticide application regime even though alternative products are commercially available. In short, development of resistance to one active ingredient is a serious concern, because it may initiate a "snowball effect", as loss of one active ingredient, and effectively an entire insecticide class, means that growers can only rotate among pesticides with a few other modes of action, and that increases the risk of resistance development to those alternative pesticides. Thus, for a range of economical, biological/ genetic reasons - growers and other stakeholders associated with the food industry should be profoundly concerned about the long-term sustainability of pest management programs relying almost exclusively on pesticide applications. There needs to be far greater awareness of the risk of resistance developing and its likely long-term cost, so that better decisions can be made on the benefits to rotating with more expensive compounds.

\section{Appreciation of the seasonal variability of pest population dynamics}

Integrated pest management (IPM) has been an applied research discipline since it was first defined by [55]. One of the initial drivers for development of IPM was the recognition of pest populations developing resistance to pesticides [56]. Many definitions and in-depth descriptions of IPM have been provided [4, 57-59]. Broadly speaking, IPM involves integration of different tactics such as pesticides, biological control, measures to prevent initial pest establishment, use of plant resistance and cultural control. Consequently, IPM requires in-depth understanding of a given target pest's biology and ecology so that cropping systems can be established and managed in ways that minimize risk of pest infestations and subsequent yield losses. IPM is expected to reduce dependence on pesticides, and [60] argued that in several respects IPM may be viewed as "IIM", or integrated insecticide management. However, the most important difference between IPM and other crop management systems is that IPM is based on two fundamental assumptions about yield loss: 1) that it is correlated with pest density and 2) predictable and therefore can be modelled and/or forecasted. Thus, an IPM approach implies that if the pest population density can be accurately estimated, it is possible to determine when and where deployment of responsive management options (such as pesticide applications and/or releases of natural enemies) are needed. Reliable and practically feasible sampling or monitoring plans are therefore needed to estimate the pest population density. The pest density estimate is converted into a decision based on an "economic threshold" (ET), which represents the pest 
density at which the value of estimated yield loss equals the cost of responsive intervention. If it is assumed that yield loss can be predicted or forecasted based on a given pest population density, then the economic injury level (EIL) can be used as benchmark for when to take action. Consequently, responsive intervention, such as applying an insecticide, should only be deployed, when/if the pest density estimate is expected to exceed the EIL or the ET. The "textbook" concept of EIL (i.e. [4] includes the following variables (Equation 2):

$$
\mathrm{EIL}=\mathrm{C} /(\mathrm{V} \times \mathrm{D} \times \mathrm{K})
$$

In which " $\mathrm{C}$ " denotes the cost of action (i.e. application of an insecticide), "V" denotes the market value of the crop, " $\mathrm{D}$ " denotes the relationships between pest density and damage, and " $\mathrm{K}$ " denotes a coefficient of unavoidable loss (between 0-1). With IPM being an approach based on knowledge about the pest density and the relationship between pest density and economic loss, we argue that costs associated with sampling and the willingness to accept risk should also be included in the calculation of EIL. In development of sequential sampling plans, it is inherently assumed that there is a positive correlation between the precision of the population density estimate and the required sampling effort. In most cases, this relationship is probably asymptotic - so the question becomes how much is gained by collecting, for instance, 25 leaf samples compared to 20, or 47 instead of 42 ? The answer to this question is not necessarily straight forward, because the "cost" or effort associated with sampling should be taken into account, and the relative cost or effort per data point is not necessarily linear. In other words, most of the sampling costs may be associated with actually driving to the field, and once you are there, it may cost almost the same to take 20 or 25 samples. However for simplicity, we have added two variables to the calculation of the EIL (Equation 3)

$$
\mathrm{EIL}=[\mathrm{C} \times(\mathrm{S} /(1-\mathrm{P}))] /(\mathrm{V} \times \mathrm{D} \times \mathrm{K})
$$

With "S" denoting the cost of collecting one sample (i.e. counting number of nymphs on a crop leaf) and "P" denotes the required precision of the sampling effort $(0<\mathrm{P}<1)$. Thus with these additions to Equation 2, it is acknowledged that "expensive" or labour intensive sampling will increase the pest population density which triggers action, and that requirements of high precision of pest population estimates will increase the needed sampling effort and therefore the the EIL. The concept of adding precision or tolerance of error to sampling methods is expanded further in sequential sampling [4, 61].

The concept of IPM - or only taking action on a when-needed basis- is supported by the fact that in most cropping systems, densities of pest species and their economic importance (expressed in crop damage or yield loss) are markedly influenced by weather and agronomic factors and therefore not constant across growing seasons or regions. Thus, in- 
dividual growers face "low risk" and "high risk" growing seasons, and this is tightly linked to the often opportunistic character of arthropod pest populations - that they are able to take advantage of certain combinations of environmental and agronomic conditions; but they also suffer under other combinations, and in those years insecticide applications may not be warranted. As an example, the diamondback moth is among the most important pests on growing canola in Australia (winter crop). [62] summarized the widely accepted hypothesis regarding the ecological mechanisms driving diamondback moths outbreaks in winter rainfall regions of Australia: in years with good summer rainfall, supporting various cruciferous plants, including wild radish, turnip weeds and volunteer canola before the growing season. These host plants provide a "green bridge" during the summer months and enable early establishment of diamondback moth populations. At the same time, good summer and autumn rainfall means that canola is planted comparatively early and therefore establishes well under those growing conditions. Canola is a highly preferred host by diamondback moth [63], so populations developing in weeds and nonagricultural habitats may migrate into canola and cause economic damage. The risk of severe diamondback moth infestations seem to be further increased if, after early rains, the canola becomes slightly drought stressed. During the last 10 years, seasonal weather patterns characterized by good summer and autumn rainfall seem to explain a couple of growing seasons with high losses in large canola growing regions due to diamondback moth infestations. However in most years, diamondback moth is not considered a major pest on a wide geographical scale. As already mentioned, diamondback moth is one of the most adaptable arthropod pests regarding insecticide treatments, as it was the first pest to develop resistance to DDT and $\mathrm{Bt}$, and, as a species, it is considered resistant to at least 82 active ingredients (may vary among local populations). Thus, for long-term sustainable management of diamondback moth, it is highly important that its somewhat sporadic pest status is taken into account and that insecticides are only applied when and where they are deemed necessary. The important aspect of arthropod pest densities only occasionally leading to significant economic losses is that it provides justification for some times (in some growing seasons and/or in some cropping systems) NOT to apply insecticides, when pest populations are below a given threshold. However, diamondback moth being a sporadic pest in canola in Western Australia is by no means a unique pest-crop system, as most insect pests vary economic importance across seasons. For a wide range of orchards pests [including a moth pest complex of peach [64] and Acrobasis nuxvorella Nuenzig (Lepidoptera: Pyralidae) in pecan [65], and field pests [including Hypera postica (Gyllenhal) (Coleoptera: Curculionidae) in alfalfa [66], and Cylindrocopturus adspersus (LeConte) (Coleoptera: Curculionidae) in sunflower [67], Diabrotica virgifera virgifera LeConte (Coleoptera: Chrysomelidae) adults in maize [68], and Sitodiplosis mosellana (Géhin) (Diptera: Cecidomyiidae) in wheat [69], there are well-established degree-day models to predict "low risk" and "high risk" growing seasons. Such degree day models represent two important notions: 1) that the economic importance of a given pest shows considerable regional and seasonal variation, and 2) that the considerable spatio-temporal variation in economic importance can be predicted/forecasted based on quantitative models. Such 
models can be used very effectively to estimate whether a particular arthropod pest in a given growing season poses a threat to a certain crop system and provide strong foundation for only using insecticides on a when-needed basis. Only applying insecticides when needed may save growers money, and it will undoubtedly reduce the risk of insecticide resistance.

\section{Applying insecticides on a when-needed basis}

Based on the description of EIL in IPM based approaches to pest management, Fig. 8a shows average pest population densities for the Scenario 2 simulations (see above) after including a pesticide spray application threshold ranging from $0-10 \%$ of the carrying capacity (11,000 pest individuals) for the particular sampling universe (i.e. a field). In other words, it was assumed that sampling was conducted and that the average number of pests per plant was used as an action threshold for insecticide application. If the action threshold $=0$, all pest generations were subjected to an insecticide application, while an action threshold $=2.5 \%$ meant that insecticide applications were only deployed if the estimated population density exceeded 275 pest individuals (or $2.5 \%$ of 11,000). Quite interestingly, the simulations suggested that using an action threshold led to slightly lower population density after 20 generations compared to a threshold $=0$. In addition, the zero threshold showed a gradual increase in population densities from 18 generations and onwards, while those simulations with a threshold showed a population density stabilizing after about 12 generations. More importantly, the increase in $\mathrm{r}$ allele frequency was markedly reduced when a threshold was used, and it stabilized at about $50 \%$, while it continued to increase in the scenarios without a threshold $=0$ (Fig. 8b). Another interesting aspect of this analysis was that with 1,000 simulations and 20 generations, there was a total of 20,000 combinations of generations and simulations, and: 1) threshold $=0$ obviously triggered 20,000 insecticide applications, 2 ) threshold $=2.5 \%$ of carrying capacity triggered 13,890 insecticide applications, 3 ) threshold $=5.0 \%$ of carrying capacity triggered 13,340 insecticide applications, and 4 ) threshold $=10 \%$ of carrying capacity triggered 12,517 insecticide applications. This means that, in addition to postponing complete insecticide failure (development of complete resistance development in the pest population), even a fairly low threshold of $2.5 \%$ of the carrying capacity reduced costs associated with insecticide applications by $31 \%[(20,000-13,890) \times 100 / 20,000]$.

This exercise highlights some of the possible benefits of allowing some individuals of the homozygous susceptible genotype (with a higher reproductive fitness) to survive. They will obviously impose some level of crop damage and therefore cause yield losses, but their beneficial "dilution effect" is clearly outlined in the results from this simple exercise. In addition, it seems plausible that only spraying when the population density is above a certain threshold may enable natural enemies to become established and at least partially suppress the target pest populations. Incorporation of a pest density threshold as part of resistance management is analogous to the use of refuges as part of managing risk of ar- 
thropod resistance in transgenic crops (see [45] for review). Of course, the potential of taking advantage of benefits from reduced insecticide application is based on the assumption that a combination of detection/monitoring and degree-day modelling can be converted into accurate and reliable decision support tools. Thus, it is paramount to envision the development of arthropod pest population growth models under field conditions as an essential part of optimizing use of insecticides - both in terms of when application is needed and as part of resistance management.
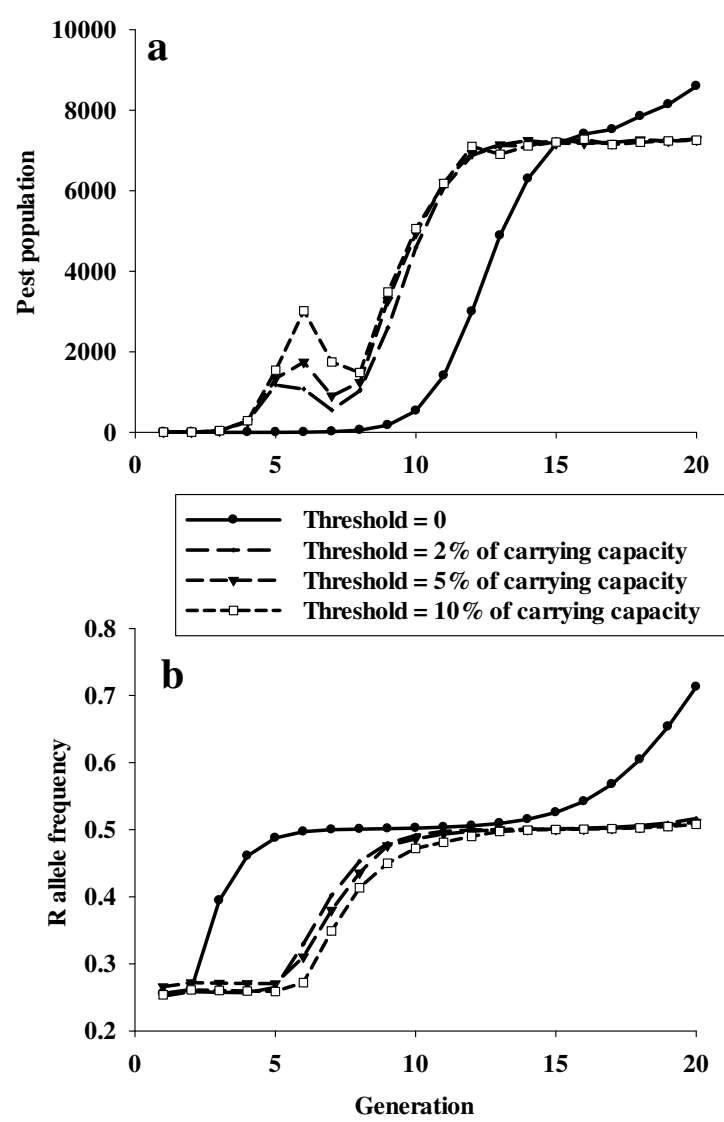

Figure 8. Effects of incorporating an action threshold

\section{Pest infestations - symptoms rather than problems}

Above, it was established that, mainly as "peace of mind" or because of operational convenience and less as a response to actual emerging pest infestations, insecticides are being 
sprayed/applied more often than what is economically justifiable and/or necessary to control target pest populations below action thresholds. In addition, we highlighted some practical/ operational circumstances, like tank mix, which may justify insecticide application even without knowing whether emerging pest populations are present or not. It was also shown, based on detailed analysis of water sensitive spray cards deployed under commercial pesticide applications, that expected performance of spray applications may often be below optimal due to quite low spray coverage and canopy penetration. That is, we have outlined the heavy reliance on insecticide applications and also shown that most of the quantitative data available in published reports suggests that insecticide spray coverages are often quite low. In many situations, the benefits of applying insecticides are clear and pest control is being effective, but for other major pests chemical control does not seem to work. Further research into the biology and ecology of these pests can provide valuable clues to how we can reduce our reliance on insecticide based management of important pests. For example, in regions of southern Australia with summer rainfall, root-feeding larvae of scarab beetles at times can destroy all the roots of pasture grasses, so that the pasture can be rolled up like a carpet. During 1970-1975 some 20,000-40,000 ha pasture were estimated to be sprayed annually at a cost of about \$AUD 10 per ha. However, research showed the presence of potentially damaging populations was only evident after the damage had occurred and spraying at this time not only failed to prevent damage but also killed valuable natural enemies [70]. Larvae of the root-feeding scarab species selectively feed on living roots of the grasses in the soil [71], which initially causes a reduction in root growth, but a reduction in foliage growth was observed only when the plants were also defoliated (grazed), and these plants are vulnerable to any periods of water stress due to lack of rainfall [72]. At times when younger larvae are feeding actively and plants are growing well damage is not evident, and it is a later time when older larvae are present that the plants may die due to drought. Spraying at this time does not prevent the appearance of damage because the plants were damaged previously. In addition when roots are growing actively and larvae are feeding strongly it is the lower densities of larvae that cause greatest reduction in the root yield [72]. A model of the interaction between plant growth, sheep grazing and insect feeding indicate that greatest impacts of the insect on pastures are occurring at low grazing pressures and low insect densities when plants are growing well [73]. An adjustment of spraying strategy is needed for these root-feeding scarabs. The redlegged earth mite is a major foliage-feeding pest in regions of southern Australia with winter rainfall, feeding on annual clovers in pastures. Potential economic losses due to redlegged earth mite damage in pastures are estimated at $\$ 200$ million a year [74]. Pesticides are applied mainly in autumn as bare earth treatment before the mites emerge or in autumn and spring as foliar sprays without any one approach to control being consistently superior. Mites feed on annual crops and pastures during the cooler wet winter but avoid the hot dry summer as diapausing eggs. Emergence of mites in autumn varies from year to year depending on rainfall and temperature, but the onset of diapause in spring in this species remains the same for any one site from year to year [75]. A very accurate prediction for the onset of summer diapause was made for redlegged earth mites based on day length and length of long term growing season everywhere in southern Australia where this species was present [76]. This model was used to give an optimal 
spring spray date for a single well timed spray, which has resulted in very effective control (over 95\%) to the populations emerging the following autumn 8 months after the spray [77]. In both of these examples growers need to make decisions to control the pests long before the actual damage occurs. The mites are easier to see than the root-feeding scarabs which may make it easier to decide on the future risk of damage occurring but the strategy in both cases is to reduce the risk of damage occurring. Growth of plants also affects the plant-insect interaction. Grazing management can affect the populations of some pasture pests, as pastures have a carrying capacity for pests as they do for sheep. Heavy grazing can be used to suppress pest populations in the pasture $[78,79]$. Other factors affecting plant growth will also interact with the populations of pests feeding on them. The risk of spider mite (Acari: Tetranychidae) infestations, have been shown to increase in response to crops being grown under drought stressed conditions [for sorghum, Sorghum bicolor (L.) Moench [80], cucumber, Cucumis sativus L. [81], pepper, Capsicum spp. [81] and strawberry, Fragaria spp. [81], ornamental plants [82], soybean, Glycine max L. [83], cowpea, Vigna unguiculata (L.) Walp [84], and maize (Zea mays L) [85, 86]. Thus, effective irrigation management could be considered a spider mite management tool. Numerous studies have demonstrated that nitrogen fertilizer tends to increase risk of spider mite infestations [87-90]. Thus application of nitrogen fertilizer will result in improved production but can lead also to the need for further cost inputs (pesticides). [91] reviewed over 2,000 studies regarding effects of potassium on pest and disease incidence in plants. In about $63 \%$ of these studies, application of potassium led to a decrease in pest pressure, but opposite and inconsistent effects of potassium applications have also been observed. The exact causes of a positive correlation between potassium deficiency level and susceptibility to pests are not fully understood, but there seems to be considerable evidence of potassium deficiency causing accumulation of soluble sugars and amino acids and interference with constituent host plant defence mechanisms [92].

Pest insects tend to feed mainly on one stage of growth of the plant. For many crop plants it is the seed which is harvested and sold and damage at this stage or post-harvest has a very direct impact on yield. Feeding damage by redlegged earth mite on seedlings can carry through to loss of seed yield by mature plants. In a carefully controlled study on yellow lupins (Lupinus luteus), redlegged earth mites at different known densities were allowed to feed for 14 days on seedlings and then removed, and the plants were grown to final seed yield 142 days after mite application [93]. This study revealed a clear negative correlation between redlegged earth mite density and yield with about $56 \%$ lower yields at the highest redlegged earth mite density. To avoid this damage the plants would have had to be sprayed with an effective miticide at the seedling stage. This is another example where the decision to spray has to be taken some time before any damage is evident. When the pest is feeding on the seed pod (as with pod borers) some plants are able to compensate. Population-level compensation is observed in cotton following feeding by Helicoverpa larvae (Lepidoptera) [94], although obviously very considerable loss of seed yield due to this species can also be seen at other times. The examples above illustrate how insecticide applications should be based on extensive knowledge about the target pest's biology, and that overall management practices can dramatically influence the susceptibility of crops to pest species. It therefore seems possible to both time insecticide applications more accurately and also re- 
duce the number of applications by managing crops so that they are less likely to become infested. This approach will obviously reduce the number of insecticide applications, and therefore also decrease the likelihood of pest populations developing resistance. In this context, it is also important to highlight the adverse effect of insecticides on populations of beneficial insects. The example given here is for adverse effects on dung feeding beetles which provide ecosystem services by dispersing and burying dung and reducing populations of dung breeding nuisance flies. Avermectins are a family of drugs used to control internal parasites of cattle, horses and sheep. Residues from these compounds that are excreted in the dung of cattle can kill both the dung breeding nuisance fly pest, Musca vetustissima, and adversely affect the breeding of introduced scarab dung beetles [95]. Several authors have expressed concern that widespread use of avermectins as cattle drenches could adversely affect the populations of recently introduced scarab dung beetles [96]. Research has shown that scarab dung beetles in southern Australia breed mainly for 2-3 months in spring, and if farmers avoid using avermectins to drench cattle in these critical months an impact on dung beetle breeding would be minimised [97]. As can be seen from these examples, it is necessary to have a good biological and ecological understanding of the pest and the crop plant in order to optimise the control of pests and reduce adverse effects of using insecticides.

\section{Conclusions}

When concerns are raised about efficacy of currently available pest management programs, it is important to remember that humans have battled arthropod pests for as long as we have had agricultural production. There are 4,500-year old records of insecticide-based management practices for control of insect pests in pre- and post-harvest agricultural products. Even biological control has been practiced for over 2,000 years [58, 59]. Yet, we have not been able to develop arthropod pest management Systems based on pesticide applications, which consistently (across many growing seasons and in most growing regions) maintain individual pest species below densities of economic concern. In stored grain, orchards, horticulture, row crops. As a consequence, we are today researching management programs for the same pests as we did 50-100 years ago, or even before that. Despite incredible technological advances and scientific innovations during the development of human civilizations, we are still unable to "outsmart" the insects and mites in our food production, processing, and storage systems. On the other hand, there are several important examples of how classical biological control has provided almost complete control of different pests (i.e. weevils to control water hyacinth infestations in rivers and lakes, parasitoids to control cassava mealybugs in Western Africa, and moths to control prickly pear in Australia). Transgenic Bt technology may be considered an encouraging exception, as it has provided remarkable control of several key coleopteran and lepidopteran pests with high levels of resistance to other insecticides. However, even here there is widely reported documentation of Bt resistance (http://www.pesticideresistance.com/irac.php), and/or examples of how secondary pests, unaffected by Bt toxins, have adapted and taken advantage of the absence of Bt-controlled competitors. Thus for growers, Bt may have solved one pest problem but at the same time 
created other problems. Even after more than 50 years of IPM, and with growing challenges with target pest populations developing resistance, it is somewhat striking that the number of documented IPM "successes" is fairly low. A simple scientific literature review search provided the following number of hits (based the literature search engine, Agricola, from 1972-2012): 1) "insecticide" = 17,629, 2) "insecticide resistance" = 4,900, 3), "IPM" = 2,243, and 4) "IPM" and "success" = 23. This recognition of our to-date inability to eliminate or completely control pests leads to an important question-what benchmarks should be used to determine whether a pest management program was successful or not? [59] highlighted this aspect as being one of the leading short-comings in current IPM programs.

It is indisputable, that insecticides are very important in our food production systems, and that they will continue to play a very important role far into the future. The purpose of this chapter is by no means to diminish their importance and the benefits associated with their usage in food production - in fact it is closer to the opposite: that exactly because of their importance and value, it is paramount that we understand how to use them effectively and that their performance is not being eroded due to resistance development. Another intended message from this chapter is that, when an insecticide "is not working" it is likely attributed to application failure rather than the insecticide not being effective against the given target pest. In short, we would be in serious trouble if we could not rely on insecticides, and that is precisely why they have to be used as wisely as possible. With the continuously growing list of insecticides becoming ineffective due to resistance, insecticides being faced out due to concerns about their adverse environmental effects, and with chemical companies having to spend increasing amounts of resources on getting new active ingredients registered for commercial use - it seems reasonable to reflect on the long-term sustainability of pest management practices based almost exclusively on insecticide applications.

\section{Author details}

Christian Nansen* and Thomas James Ridsdill-Smith

*Address all correspondence to: christian.nansen@uwa.edu.au

The University of Western Australia, School of Animal Biology and the UWA Institute of Agriculture, Perth, Western Australia, Australia

\section{References}

[1] Nansen C, Vaughn, K, Xue, Y, Rush, C, Workneh, F, Goolsby, J, Troxclair, N, Anciso, J, Gregory, A, Holman, D, Hammond, A, Mirkov, E, Tantravahi, P, Martini, X. A decision-support tool to predict spray deposition of insecticides in commercial potato fields and its implications for their performance. Journal of Economic Entomology 2011;104:1138-45. 
[2] Munoz IT, Mas, N, Garcia-Reyes, J, Molina-Diaz, J F, Fernandez-Alba, A, Amadeo, R. Potential chemical and microbiological risks on human health from urban wastewater reuse in agriculture. Case study of wastewater effluents in Spain. Journal of environmental science and health Part B: Pesticides, food contaminants, and agricultural wastes 2010;45:300-9.

[3] Smith D, Novotnaj, R, Smith, G K. Preharvest food safety: What do the past and the present tell us about the future? Journal of Agromedicine 2010;15:275-80.

[4] Pedigo L, Rice, M. Entomology and Pest Management. Fifth ed: Prentice Hall; 2006.

[5] Wold SJ, Hutchison, W D. Comparison of economic and plant phenology-based thresholds for management of Lygus lineolaris (Hemiptera: Miridae) in Minnesota strawberries. Journal of Economic Entomology 2003;96:1500-9.

[6] Antwi FB, Olson, D L, Knodel J J. Comparative evaluation and economic potential of ecorational versus chemical insecticides for crucifer flea beetle (Coleoptera: Chrysomelidae) management in canola. Journal of Economic Entomology 2007;100:710-6.

[7] Reay-Jones FPF, Way, M O, Reagan, T E. Economic assessment of controlling stem borers (Lepidoptera: Crambidae) with insecticides in Texas rice. Crop Protection 2007;26:963-70.

[8] Derksen R, Zhu, H, Ozkan, H E, Hammond, R B, Dorrance, A E, Spongberg, A Determining the influence of spray quality, nozzle type, spray volume, and air-assisted application strategies on deposition of pesticides in soybean canopy. Transactions of the ASABE 2008;51:1529-37.

[9] Yu Y, Zhu, H, Ozkan, H E, Derksen, R C, Krause, C R. Evaporation and deposition coverage area of droplets containing insecticides and spray additives on hydrophilic, hydrophobic, and crabapple leaf surfaces. Transactions of the ASABE 2009;52:39-49.

[10] Renton M, Diggle, A, Sudheesh, M, Powles, S. Does cutting herbicide rates threaten the sustainability of weed management in cropping systems? Journal of Theoretical Biology 2011;283:14-27.

[11] Rebetzke GJ, Botwright, T L, Moore, C S, Richards, R A, Condon, A G. Genotypic variation in specific leaf area for genetic improvement of early vigour in wheat. Field Crops Research 2004;88:179-89.

[12] Brittain CA, Vighi, M, Bommarco, R, Settele, J, Potts, S G. Impacts of a pesticide on pollinator species richness at different spatial scales. Basic and Applied Ecology 2010;11:106-15.

[13] Whalon ME, Mota-Sanchez, D, Hollingworth, R M. Analysis of global pesticide resistance in arthopods. In: Whalon ME, Mota-Sanchez, D, Hollingworth, R M, editor. Global pesticide resistance in arthopods. Oxfordshire, UK: CABI; 2008. p. 5-32.

[14] Hoffman WC, Hewitt, A J Comparison of three imaging systems for water-sensitive papers. Applied Engineering in Agriculture 2005;21:961-4 
[15] Latheef MA, Carlton, J B, Kirk, I W, Hoffmann, W C. Aerial electrostatic-charged sprays for deposition and efficacy against sweet potato whitefly (Bemisia tabaci) on cotton. Pest Management Science 2008;65:744-52.

[16] Latheef MA, Kirk, I W, Bouse, L F, Carlton, J B, Hoffmann, W C. Evaluation of aerial delivery systems for spray deposition and efficacy against sweet potato whitefly on cotton. Applied Engineering in Agriculture 2008;24:415-22.

[17] Wolf RE, Daggupati, N P. Nozzle type effect on soybean canopy penetration. Applied Engineering in Agriculture 2009;25:23-30.

[18] Powles SB, Yu, Q Evolution in action: plants resistant to herbicides. Annual Review of Plant Biology 2010;61:317-47.

[19] Hollingworth RM, Dong, K. The biochemical and molecular genetic basis of resistance to pesticides in arthropods. In: Whalon ME, Mota-Sanchez, D, Hollingworth, R $\mathrm{M}$, editor. Global pesticide resistance in arthropods Oxfordshire, UK: CAB International; 2008. p. 40-89.

[20] Georghiou OP. The evolution of resistance to pesticides. Annual Review of Ecology, Evolution, and Systematics 1972;3:133-68.

[21] Ross MH. Laboratory studies on the response of German cockroaches (Dictyoptera: Blattellidae) to an abamectin gel bait. Journal of Economic Entomology 1993;86:767-71.

[22] Silverman J, Bieman, D N. Glucose aversion in the German cockroach, Blattella germanica. Journal of Insect Physiology 1993;39:925-33.

[23] Wang C, Scharf, M E, Bennett, G W. Behavioral and physiological resistance of the German cockroach to gel baits (Blattodea: Blattellidae). Journal of economic entomology 2004;97:2067-72.

[24] Gharalari AH, Nansen, C, Lawson, D S, Gilley, J, Munyaneza, J E, Vaughn, K. Knockdown mortality, repellency and residual effects of insecticides for control of adult Bactericera cockerelli (Homoptera: Psyllidae). Journal of Economic Entomology 2009;102:1032-8.

[25] Melander AL. Can insects become resistant to sprays? Journal of Economic Entomology 1914;7:167-73.

[26] Georghiou GP, Taylor, C E. Pesticide resistance as an evolutionary phenomenon. Proceedings of the 15th International Conference of Entomology. Washington, DC1977. p. 759-85.

[27] Roush RT, McKenzie, J A. Ecological genetics of insecticide and acaricide resistance. Annual Review of Entomology 1987;32:361-80.

[28] Georghiou GP, Lagunes-Tejeda, A. The occurrence of resistance to pesticides in arthropods. An index of cases reported through 1989. Rome, Italy: Food and Agriculture Organization of the United Nations; 1991. 
[29] Ankersmit OW. DDT resistance in Plutella maculipennis (Curt.) (Lepidoptera) in Java. Bulletin of Entomological Research 1953;44:421-5.

[30] Johnson DR. Plutella maculipennis resistance to DDT in Java. Journal of Economic Entomology 1953;46:176.

[31] Zalucki MP, Adamson, D, Furlong, M J. The future of IPM: whither or wither? Australian Journal of Entomology 2009;48:85-96.

[32] Kirsch K, Schmutterer, H Low efficacy of a Bacillus thuringiensis (Berl.) formulation in controlling the diamondback moth, Plutella xylostella (L.) in the Philippines. Journal of Applied Entomology 1988;105:249-55.

[33] Kirsch K SH. Low efficacy of a Bacillus thuringiensis (Berl.) formulation in controlling the diamondback moth, Plutella xylostella (L.) in the Philippines. Journal of Applied Entomology 1988;105:249-55.

[34] Ferre JM, Real, D, Rie, J V, Jansens, S, Peferoen, M. Resistance to the Bacillus thuringiensis bioinsecticides in a field population of Plutella xylostella is due to a change in a midgut membrane receptor. Proceedings of the National Academy of Science 1991;88:5119-23.

[35] Jallow MFA, Hoy, C W. Quantitative genetics of adult behavioral response and larval physiological tolerance to permethrin in diamondback moth (Lepidoptera : Plutellidae). Journal of Economic Entomology 2006;99:1388-95.

[36] Jallow MFA, Hoy, C W. Indirect selection for increased susceptibility to permethrin in diamondback moth (Lepidoptera : Plutellidae). Journal of Economic Entomology 2007;100:526-33.

[37] Hostetler ME, Brenner, R J. Behavioral and physiological resistance to insecticides in the german cockroach (Dictyoptera, Blattellidae) - An experimental reevaluation. Journal of Economic Entomology 1994;87:885-93.

[38] Guedes NMP, Guedes, R N C, Silva, L B, Cordeiro, E M G. Deltamethrin-induced feeding plasticity in pyrethroid-susceptible and -resistant strains of the maize weevil, Sitophilus zeamais. Journal of Applied Entomology 2009;133:524-32.

[39] Nansen C, Hinson, B, Davidson, D, Vaughn, K, Hosseini, A. Novel approaches to application and performance assessment of insecticide applications to crop leaves. Journal of Economic Entomology 2010;103:219-27.

[40] Martini X, Kincy, N, Nansen, C. Quantitative impact assessment of spray coverage and pest behavior on contact pesticide performance. Pest Management Science 2012.

[41] Georghiou GP, Taylor, C E. Genetic and biological influences in the evolution of insecticide resistance. Journal of Economic Entomology 1976;70:319-23.

[42] Carrière Y, Tabashnik, B E. Reversing insect adaptation to transgenic insecticidal plants. Proceedings of the Royal Society B: Biological Sciences 2001;268:1475-80. 
[43] Tabashnik BE, Dennehy, T J, Carrière, Y. Delayed resistance to transgenic cotton in pink bollworm. Proceedings of the National Academy of Science 2005;102:15389-93.

[44] Gould F, Cohen, M B, Bentur, J S, Kennedy, G G, Duyn, J van. Impact of small fitness costs on pest adaptation to crop varieties with multiple toxins: a heuristic model. Journal of Economic Entomology 2006;99:2091-9.

[45] Gassmann AJ, Carrière, Y, Tabashnik, B E. Fitness costs of insect resistance to Bacillus thuringiensis. Annual Review of Entomology 2009;54:147-63.

[46] Tabashnik BE. Computer simulation as a tool for pesticide resistance management. Washington, DC: National Academic Press; 1986.

[47] Tabashnik BE, Croft, B A. Managing pesticide resistance crop arthropod complexes: interactions between biological and operational factors. Environmental Entomology 1982;11:137-44.

[48] Kirnak H, Demirtas, M N. Effects of different irrigation regimes and mulches on yield and macronutrition levels of drip-irrigated cucumber under open field conditions. Journal of Plant Nutriton 2006;29:1675-90.

[49] Zhu L, Liang, Z S, Xu, X, Li, S H. Relationship between carbon isotope discrimination and mineral content in wheat grown under three different water regimes. Journal of Agronomy and Crop Science 2008;194:421-8.

[50] Wang Y, Liu, F, Andersen, M N, Jensen, C R. Improved plant nitrogen nutrition contributes to higher water use efficiency in tomatoes under alternate partial root-zone irrigation. Functional Plant Biology 2010;37:175-82.

[51] Waraich EA, Ahmad, R, Saifullah, Ahmad, S, Ahmad, A Impact of water and nutrient management on the nutritional quality of wheat. Journal of Plant Nutrition 2010;33:640-53.

[52] Holechek JL, Estell, R E, Kuykendall, C B, Valdez, R, Cardenas, M, Nunez-Hernandez, G. Seeded wheatgrass yield and nutritive quality on new mexico big sagebrush range. Journal of Range Management 1989;42:118-22.

[53] Mayland HF, Asay, K H, Clark, D H. Seasonal trends in herbage yield and quality of agropyrons. Journal of Range Management 1992;45:369-74.

[54] Zehnder CB, Hunter, M D. Effects of nitrogen deposition on the interaction between an aphid and its host plant. Ecological Entomology 2008;33:24-30.

[55] Stern VM, Smith, R F, Bosch, R van den, Hagen, K S. Integrated Control Concept. Hilgardia 1959;29:81-101.

[56] Dent D. Insect pest management. Second ed. Ascot, UK: CABI Publishing; 1999.

[57] Kogan M. Integrated pest management theory and practice. Entomologia Experimentalis et Applicata 1988;49:59-70. 
[58] Kogan M. Integrated pest management: historical perspectives and contemporary developments. Annual Review of Entomology 1998;43:243-70.

[59] Walter GH. Insect pest management and ecological research. Cambridge, UK: Cambridge University Press; 2003.

[60] New TR. Insects and pest management in Australian agriculture. Oxford, UK: Oxford University Press; 2002.

[61] Nansen C, Meikle, W G, Campbell, J, Phillips, T W, Subramanyam, B. A binomial and species-independent approach to trap capture analysis of flying insects. Journal of Economic Entomology 2008;101:1719-28.

[62] Gu H, Fitt, G P, Baker, G H Invertebrate pests of canola and their management in Australia: a review. Australian Journal of Entomology 2007;46:231-43.

[63] Sarfraz M, Dosdall, L M, Keddie, B A Resistance of some cultivated Brassicaceae to infestations by Plutella xylostella (L.) (Lepidoptera: Plutellidae). Journal of Economic Entomology 2007;100:215-24.

[64] Damos PT, Savopoulou-Soultani, M. Development and statistical evaluation of models in forecasting moth phenology of major lepidopterous peach pest complex for Integrated Pest Management programs. Crop Protection 2010;29:1190-9.

[65] Knutson AE, Muegge, M A. A degree-day model initiated by pheromone trap captures for managing pecan nut casebearer (Lepidoptera: pyralidae) in pecans. Journal of Economic Entomology 2010;103:735-43.

[66] Stilwell AR, Wright, R J, Hunt, T E, Blankenship, E E. Degree-day requirements for alfalfa weevil (Coleoptera: Curculionidae) development in eastern Nebraska. Environmental Entomology 2010;39:202-9.

[67] Merrill SC, Gebre-Amlak, A, Armstrong, J S, Peairs, F B. Nonlinear degree-day models for postdiapause development of the sunflower stem weevil (Coleoptera: Curculionidae). Journal of Economic Entomology 2010;103:302-7.

[68] Stevenson DE, Michels, G E, Bible, J B, Jackman, J A, Harris, M K. Physiological time model for predicting adult emergence of western corn rootworm (Coleoptera: Chrysomelidae) in the Texas High Plains. Journal of Economic Entomology 2008;101:1584-93.

[69] Elliott RH, Mann, L, Olfert, O. Calendar and degree-day requirements for emergence of adult wheat midge, Sitodiplosis mosellana (Gehin) (Diptera: Cecidomyiidae) in Saskatchewan, Canada. Crop Protection 2009;28:588-94.

[70] Marsden JS, Martin, G E, Parham, D J, Ridsdill-Smith, T J, Johnson, B G. Scarab beetle research. In Returns on Australian Agricultural Research. Melbourne, Australia: CSIRO Publishing; 1980. p. 41-4. 
[71] Ridsdill-Smith TJ. Selection of living grass roots in the soil by larvae of Sericesthis nigrolineata (Coleoptera: Scarabaeidae). Entomologia Experimentalis et Applicata $1975 ; 18: 75-86$.

[72] Ridsdill-Smith TJ. Effects of root-feeding by scarabaeid larvae on growth of perennial ryegrass plants. Journal of Applied Ecology 1977;14:73-80.

[73] Roberts RJ, Ridsdill-Smith, T J. Assessing pasture damage and losses of animal production caused by pasture insects. In Animal production losses caused by pasture insects. In: Crosby TK, Pottinger, R P, editor. 2nd Australasian Conference on grassland invertebrate ecology. Govt Printer, Wellington, New Zealand1979. p. 124-5.

[74] Ridsdill-Smith TJ. Biology and control of Halotydeus destructor (Tucker) (Acarina: Penthaleidae): a review. Experimental and Applied Acarology 1997;21:195-224.

[75] Ridsdill-Smith TJ, Annells, A J. Seasonal occurrence and abundance of redlegged earth mite Halotydeus destructor (Acari: Penthaleidae) in annual pastures of southwestern Australia. Bulletin of Entomological Research 1997;87:413-23.

[76] Ridsdill-Smith TJ, Pavri, C, Boer, E de, Kriticos, D. Predictions of summer diapause in the redlegged earth mite, Halotydeus destructor (Acari: Penthaleidae), in Australia. Journal of Insect Physiology 2005;51:717-26.

[77] Ridsdill-Smith TJ, Hoffmann, A A, Mangano, G P, Gower, J M, Pavri, C C, Umina, P A. Strategies for control of redlegged earth mite in Australia. Australian Journal of Experimental Agriculture 2008;48:1506-13.

[78] Roberts RJ, Morton, R. Biomass of larval Scarabaeidae (Coleoptera) in relation to grazing pressures in temperate, sown pastures. Journal of Applied Ecology $1985 ; 22: 863-74$.

[79] Barlow ND. Pastures, pests and productivity: simple grazing models with two herbivores. New Zealand Journal of Ecology 1987;10:43-55.

[80] Stiefel VL, Margolies, D C, Bramel-Cox, P J. Leaf temperature affects resistance to the Banks grass mite (Acari: Tetranychidae) on drought-resistant grain sorghum. Journal of Economic Entomology 1992;85:2170-84.

[81] Palevsky E, Walzer, A, Gal, S, Schausberger, P. Evaluation of dry-adapted strains of the predatory mite Neoseiulus californicus for spider mite control on cucumber, strawberry and pepper. Experimental and Applied Acarology 2008;45:15-27.

[82] Gillman JH, Dirr, M A, Braman, S K. Gradients in susceptibility and resistance mechanisms of Buddleia L Taxa to the two-spotted spider mite (Tetranychus urticae Koch). Journal of American Society of Horticultural Science 1999;124:114-21.

[83] Klubertanz TH, Pedigo, L P, Carlson, R E. Effects of plant moisture stress and rainfall on population dynamics of the two-spotted spider mite (Acari: Tetranychidae). Environmental Entomology 1990;19:1773-9. 
[84] Abdel-Galil FA, Amro, M A M, Abdel-Moniem, A H. Effect of drought stress on the incidence of certain arthropod pests and predators inhabiting cowpea plantations. Archives Of Phytopathology And Plant Protection 2008;40:207-14.

[85] Perring TM, Holtzer, T O, Toole, J L, Norman, J L. Relationships between corn-canopy microenvironments and Banks grass mite abundance. Environmental Entomology 1986;15:79-83.

[86] Toole J, Norman, L J, Holtzer, M T O, Perring, T M. Simulating Banks grass mite (Acari: Tetranychidae) population dynamics as a subsystem of a crop canopy-microenvironment model. Environmental Entomology 1984;13:329-37.

[87] Garman P, Kennedy, B H. Effect of soil fertilization on the rate of reproduction of the two-spotted spider mite. Journal of Economic Entomology 1949:157-8.

[88] Rodriguez JG, Neiswander, R B. The effect of soil soluble salts and cultural practices on mite populations on hothouse tomatoes. Journal of Economic Entomology 1949;42:511-26.

[89] Chen Y, Opit, G P, Jonas, V M, Williams, K A, Nechols, J R, Margolies, D C. Two spotted spider mite population level, distribution, and damage on ivy geranium in response to different nitrogen and phosphorus fertilization regimes. Journal of Economic Entomology 2007.

[90] Machado S, Bynum, E D J, Archer, T L, Lascano, R J, Wilson, L T, Bordovsky, J, Segarra, E, Bronson, K, Nesmith, D M, Xu, W. Spatial and temporal variability of corn grain yield: site-specific relationships of biotic and abiotic factors. Precision Agriculture 2000;2:359-76.

[91] Perrenoud S. Potassium and Plant Health. Basel, Switzerland: International Potash Institute; 1990.

[92] Amtmann A, Troufflard, S, Armengaud, P. The effect of potassium nutrition on pest and disease resistance in plants. Physiologia Plantarum 2008;133:682-91.

[93] Liu A, Ridsdill-Smith, T J, Nicholas, D C. Effect of seedling damage by redlegged earth mite, Halotydeus destructor, on subsequent growth and development of yellow lupin, Lupinus luteus, in the glasshouse. Australian Journal of Agricultural Research 2000;51:113-8.

[94] Sadras VO. Population-level compensation after loss of vegetative buds: interactions among damaged and undamaged cotton neighbours. Oecologia 1996;106:417-23.

[95] Ridsdill-Smith TJ. Survival and reproduction of Musca vetustissima Walker (Diptera: Muscidae) and a scarabaeine dung beetle in dung of cattle treated with avermectin B1. Journal of the Australian Entomolocical Society 1988;27:175-8.

[96] Wardhaugh KG, Ridsdill-Smith, T J. Antiparasitic drugs and the livestock industry cause for concern? Australian Veterinary Journal 1998;76:259-61. 
[97] Ridsdill-Smith TJ. Effects of avermectin residues in cattle dung on dung beetle (Coleoptera: Scarabaeidae) reproduction and survival. Veterinary Parasitology 1993;48:127-37. 
